\title{
REVIEW
}

\section{Turbulent mixing in experimental ecosystem studies}

\author{
Lawrence P. Sanford* \\ University of Maryland, Center for Environmental Science, Horn Point Laboratory, PO Box 775, Cambridge, \\ Maryland 21613, USA
}

\begin{abstract}
Turbulent mixing is an integral aspect of aquatic ecosystems. Turbulence affects ecosystem features ranging from phytoplankton blooms at large scales through microscale interactions in the plankton. Enclosed experimental ecosystems, if they are to mimic the function of natural ecosystems, also must mimic natural turbulence and its effects. Large-scale velocity gradients and unstable buoyancy fluxes generate turbulent mixing in nature, most often at the surface and bottom boundaries and in the pycnocline. Large eddy sizes are controlled by the mixed layer depth, boundary layer thickness, or overturning length in the pycnocline. Turbulent energy cascades through smaller and smaller eddy scales until it can be dissipated by molecular viscosity at the smallest scales. In contrast, artificial apparatuses frequently are used to generate turbulent mixing in the interior of experimental ecosystem enclosures. Large eddy sizes are controlled by the size of the generation apparatus, and they usually are much smaller than in nature. Mismatched large eddy length scales and differences in turbulence generation mechanisms are responsible for the difficulties in mimicking natural turbulent mixing in experimental enclosures. The 2 most important turbulence parameters to consider in experimental ecosystem research are overall mixing time, $T_{m}$ and turbulence dissipation rate, $\varepsilon$. If the levels, spatial distributions, and temporal variability of $T_{m}$ and $\varepsilon$ can be matched between an enclosure and the natural system it is to model, then potential mixing artifacts can be minimized. An important additional consideration is that benthic ecosystems depend on the time-averaged boundary layer flow as much as the turbulence. Existing designs for mixing experimental ecosystems are capable of reasonably representing some aspects of natural turbulent mixing. Paddle and grid stirring are the best available techniques for water column mixing, and flumes are best for benthic turbulence. There is no design at present that represents both environments adequately. More work also is needed on mixing of flexiblewall in situ enclosures. A more serious problem, however, is that turbulent mixing in experimental ecosystem studies too often is ignored, inadequately characterized, or unreported. Several methods are available for reasonable characterization of mixing in enclosures without sophisticated technology, and the technology for direct velocity measurements is becoming more accessible. Experimental ecosystem researchers should make a concerted effort to implement, characterize, and report on turbulent mixing in their enclosures.
\end{abstract}

KEY WORDS: Turbulent mixing - Mesocosms Experimental ecosystems - Turbulence dissipation rate . Mixing time Biological-physical interaction Mass transfer

\section{INTRODUCTION}

Aquatic ecologists and toxicologists have a long history of using experimental ecosystems to explore the dynamics of aquatic ecosystems and mechanisms controlling those dynamics (Banse 1982, SCOR Working Group 85 1990, Daehler \& Strong 1996). In comparison

\footnotetext{
-E-mail: Isanford@hpl.umces.edu
}

with in situ studies, capturing and containing a piece of the natural aquatic environment gives experimental ecosystems the distinct advantages of controllability, replicability, and freedom from advective changes (Guanguo 1990, Oviatt 1994). However, isolating a small piece of an ecosystem from its natural environment risks a series of artifacts that may or may not affect seriously the course of an experiment (Conover \& Paranjape 1977, Carpenter 1996). Mixing is one aspect of the natural aquatic environment that is 
important for realistic experimental ecosystem behavior (Eppley et al. 1978, Bakke 1990, Lasserre 1990) and at the same time a challenge to generate and control in experimental containers (Steele et al. 1977, Nixon et al. 1980, Howarth et al. 1993).

Mixing in natural water bodies nearly always is turbulent. Turbulence is generated by unstable excess physical energy at large scales. This energy is transferred to smaller and smaller scales through a process of cascading instability, saturating all intermediate scales of motion, until it can be dissipated into heat by molecular viscosity (Richardson 1922, Batchelor 1967).

Because of the broad range of scales involved, turbulence affects ecosystem features ranging from basinscale phytoplankton blooms to the micro-environment of the plankton. Turbulent mixing promotes rapid mixing and dispersion at large scales (Okubo 1980, Platt 1981, Lewis et al. 1984a, b, Bennett \& Denman 1989). Turbulence plays an important role in mass transfer processes at all scales (Jorgensen \& Revsbech 1985, Jaehne et al. 1987, Mann \& Lazier 1991, Dade 1993, Denman \& Gargett 1995, Karp-Boss et al. 1996). Turbulence influences small-scale processes through its roles in predator-prey interaction (Rothschild \& Osborn 1988, Browman 1996, Dower et al. 1997), particle capture (Shimeta \& Jumars 1991), aggregation and disaggregation (Kiørboe 1993, MacIntyre et al. 1995), small-scale patchiness (Moore et al. 1992, Squires \& Yamazaki 1995), and species-specific growth inhibition (Gibson \& Thomas 1995). Turbulence and turbulent mixing are arguably equal in importance to light, temperature, salinity, and nutrient concentrations.

Simulating natural small-scale turbulence and its effects in experimental enclosures is straightforward (Hwang et al. 1994, Peters \& Gross 1994). Small-scale turbulence is approximately isotropic and homogeneous, i.e. statistically independent of direction and spatially uniform (Landahl \& Mollo-Christensen 1986. Kundu 1990). Turbulence characteristics at small scales are determined by the rate of turbulent energy dissipation, $\varepsilon$, and the kinematic viscosity of the fluid, $v$, and do not depend on the turbulence generation mechanism.

In contrast, generation of realistic large-scale turbulence in experimental ecosystem enclosures can be a challenge, especially if a realistic turbulent cascade also is of interest. Stirring by large eddies is responsible for the rapidity of turbulent mixing (e.g. Garrett 1989). Problems arise at the reduced scale of experimental ecosystems because characteristic length and time scales of large eddies are related to the largest scales of the flow. For example, the size of the largest eddies in a turbulent boundary layer is set by the boundary layer thickness, and a characteristic large eddy recurrence interval is set by the ratio of the boundary layer thickness to the mean flow speed (Cantwell 1981). A well-designed $15 \mathrm{~cm}$ deep laboratory flume can simulate a $15 \mathrm{~cm}$ deep natural flow accurately, but the effects of the large eddies in a $15 \mathrm{~m}$ deep tidal channel are much more difficult to mimic.

There also are significant differences between natural turbulence generated by vertical shear of a horizontal mean flow (e.g. at the surface, pycnocline, or bottom) and turbulence generated by a paddle or grid stirring the interior of an experimental ecosystem (Brumley \& Jirka 1987, Fernando 1991). These differences particularly are important for transport across interfaces (Jaehne et al. 1987, Dade 1993) and for benthic ecology, where the time-averaged boundary layer flow can be as important as the turbulence (Snelgrove \& Butman 1994).

It is unreasonable to expect that any single mixing design for an enclosed experimental ecosystem will reproduce all of the important characteristics of natural turbulence. It is, however, quite reasonable to ask that aquatic ecologists understand the choices that must be made with regard to mixing and the potential consequences of making such choices. My intent in this paper is to provide a framework for exploring these choices and consequences. An overview of relevant characteristics and scales of natural turbulence follows this introduction. I then discuss the meaning and use of important turbulence scales for experimental ecosystem studies, and follow up with a discussion of some of the available techniques for generating and quantifying turbulent mixing in experimental ecosystems. Because of its broad scope, this paper only briefly addresses each topic. I have attempted to provide more in-depth references whenever possible.

\section{CHARACTERISTICS AND SCALES OF NATURAL TURBULENCE}

\section{Turbulence generation}

Turbulence in nature generally is classified as shear generated or buoyancy generated, or some combination of the two. The likelihood of turbulence and the intensity of turbulence are expressed in terms of nondimensional ratios between stabilizing and destabilizing forces. The most common of these ratios are named after the fluid dynamicists credited with their discovery.

Unstratified shear-generated turbulence is common in the wind-mixed surface layer, the bottom boundary layer, and in flow around obstacles and through openings. The onset and intensity of unstratified shear turbulence are governed by the Reynolds number of the flow, 


$$
\operatorname{Re}=\frac{U L}{\mathrm{~V}}
$$

where $U$ is some characteristic velocity scale (e.g, the average flow speed in $\mathrm{m} \mathrm{s}^{-1}$ ), $L$ is some characteristic length scale (e.g. the depth in $\mathrm{m}$ ), and $v$ is the molecular kinematic viscosity (in $\mathrm{m}^{2} \mathrm{~s}^{-1}$ ). The Reynolds number may be thought of as the ratio of destabilizing inertia to stabilizing viscosity. Reynolds numbers frequently are named after the length scale of interest, such that the Reynolds number for a horizontal flow of speed $U$ in water of depth $h\left(R e_{h}=U h / v\right)$ is the depth Reynolds number. Oftentimes several Reynolds numbers may be defined, each controlling a different aspect of the turbulence. In the present example a second Reynolds number based on the bottom roughness height may be defined (the roughness Reynolds number) which controls the state (smooth or rough) of the turbulent flow very near the bottom boundary (Nowell. \& Jumars 1984) and mass transfer across that boundary (Dade 1993).

Most unstratified shear flows in nature are turbulent. For example, flow in a water column of depth $h$ is laminar (non-turbulent) if the depth Reynolds number $\left(R e_{h}\right)$ is $<500$, turbulent if $R e_{h}>2000$, and transitional between laminar and turbulent for intermediate $R_{h}$ (Smith 1975). Setting $v=10^{-6} \mathrm{~m}^{2} \mathrm{~s}^{-1}$ (a typical value in water), even a slow, shallow flow with $U=0.02 \mathrm{~m} \mathrm{~s}^{-1}$ and $h=0.1 \mathrm{~m}$ has a Reynolds number of 2000 and is very likely turbulent.

Turbulence also can be generated by shear in the presence of stable stratification. In fact, stably stratified shear turbulence is the predominant form of turbulence in the ocean, where it controls mixing across the pycnocline. As a result, a great deal of research has concentrated on this subject in recent years isee reviews by Hopfinger 1987, Abraham 1988, Gargett 1989, Fernando 1991). The most important parameter controlling turbulence generation in the presence of stable stratification is the Richardson number,

$$
R i=\frac{-\frac{g}{\rho} \frac{\mathrm{d} \rho}{\mathrm{d} z}}{\left(\frac{\mathrm{d} U}{\mathrm{~d} z}\right)^{2}}=\frac{N^{2}}{\left(\frac{\mathrm{d} U}{\mathrm{~d} z}\right)^{2}}
$$

where $g$ is gravitational acceleration (in $\mathrm{m} \mathrm{s}^{-2}$ ), $\rho$ is the density of the water (in $\mathrm{kg} \mathrm{m}^{-3}$ ), $z$ is distance normal to the plane of motion of $U$ ( $z$ usually is taken as the vertical direction, positive upwards, in $m$ ), and $N$ is the BruntVaisala frequency (a measure of water column stability and the natural frequency of oscillation of a stably stratified water column, in $\mathrm{s}^{-1}$ ). The Richardson number may be thought of as the ratio of stabilizing stratification to destabilizing shear. $R i \gg 0.25$ indicates strong stability and $R i<0.25$ usually indicates breakdown of the flow into turbulence. In general, there are multiple possible sources of shear in natural flows, which interact with the stratification and with each other in complex ways (Dyer \& New 1986, Geyer \& Smith 1987)

Turbulence generated by unstable buoyancy fluxes also is common in nature. Examples include overturning of the surface mixed layer due to outward heat flux (Taylor \& Stephens 1993, Peters et al. 1994) or increases in near surface salinity caused by evaporation or freezing. These processes result in unstable density profiles with heavier water over lighter water. The onset and intensity of buoyancy driven turbulence are controlled by the Rayleigh number,

$$
R a=\frac{g \frac{\Delta \rho}{\rho} h^{3}}{D_{\rho} \nu}=\frac{g \alpha \Delta T h^{3}}{D_{I !} \nu}
$$

where $\Delta \rho / \rho$, the normalized unstable density difference over depth $h$, is written as $\alpha \Delta T$ for an imposed temperature difference $\Delta T$ (in ${ }^{\circ} \mathrm{C}$ ) in a fluid with thermal expansion coefficient $\alpha\left(\mathrm{in}^{\circ} \mathrm{C}^{-1}\right)$, and the molecular diffusivity of mass $D_{p}$ (in $\mathrm{m}^{2} \mathrm{~s}^{-1}$ ) is written as the molecular thermal diffusivity $D_{H}\left(\right.$ in $\mathrm{m}^{2} \mathrm{~s}^{-1}$ ) for the same situation. The Rayleigh number may be thought of as the ratio of the tendency for the water column to overturn to the tendency for diffusion to eliminate unstable density differences. Well-defined convective rolls develop for $R a>1.7 \times 10^{3}$, and the flow becomes fully turbulent for $R a>10^{6}$ (Landahl \& Mollo-Christensen 1986). For example, taking $\alpha=2 \times 10^{-4}{ }^{\circ} \mathrm{C}^{-1}$ and $D_{H}=1.45 \times$ $10^{-7} \mathrm{~m}^{2} \mathrm{~s}^{-1}$ (fresh water at $20^{\circ} \mathrm{C}$; Chapman 1974), a temperature increase of $\Delta T=0.01^{\circ} \mathrm{C}$ from the surface to $h=0.2 \mathrm{~m}$ depth would correspond to $R a=1.1 \times 10^{6}$ and fully turbulent mixing would be expected.

\section{Turbulence length scales and spectra}

In unstratified turbulence, the size of the largest eddies, $l$ (in $\mathrm{m}$ ), usually approximates the overall. scale of the flow, i.e. the depth of the water column, size of an obstacle, thickness of the bottom boundary layer, depth of the surface mixed layer, etc. In the presence of stable stratification, the largest eddies tend to be smaller than the overall scale of the flow. This is because the largest eddies lose a substantial portion of their energy working against the stratification (Turner 1973). The maximum length scale for the largest eddies in stably stratified turbulence is known as the Ozmidov length,

$$
l_{R}=\left(\frac{\varepsilon}{N^{3}}\right)^{\frac{1}{2}}
$$

(Turner 1973, Abraham 1988, Weinstock 1992), where $\varepsilon$ is the energy dissipation rate of the turbulence (in 
$\left.m^{2} s^{-3}\right)$ ( $\varepsilon$ is discussed below). If velocity data are available, I also may be defined statistically as the integral length scale of the turbulent velocity field.

$$
l=\frac{1}{u_{R}^{2} M S} \int_{0}^{\infty} u\left(x_{u}\right) u\left(x_{0}+x\right) d x
$$

where $u_{\text {RNS }}$ is the root mean square of the $u$ velocity fluctuations, $u$ is a velocity component (parallel to the $x$ direction or perpendicular to the $x$ direction, in $\mathrm{m} \mathrm{s}^{-1}$ ), $x_{0}$ is an arbitrary fixed position, and $x$ is distance away from that position (in m; Tatterson 1991). Another way of interpreting Eq. (5) is to think of $l$ as the auto-correlation length scale of the turbulent velocity field, or the distance at which velocity fluctuations are no longer correlated.

Large eddies in turbulent flows contain the most energy. This is because flows usually are most unstable at large scales, and large eddies are the first to be generated. For example, large length scales, $L$, in Eq. (1) lead to large values of $R e$ and a greater likelihood of turbulence. Large depths $h$ in Eq. (3) have an even greater effect, since $R a$ depends on $h^{3}$. If there is sufficient energy in the flow, the large eddies themselves become unstable and break down into smaller eddies, which in turn become unstable and break down into smaller eddies, etc.; this process is known as the cascade of turbulent energy (Richardson 1922). Large eddies frequently are inhomogeneous and anisotropic, reflecting the character of their generation mechanism (e.g. Grant et al. 1962, Townsend 1976). Once energy has entered the turbulent field and the turbulent energy cascade to smaller and smaller scales has begun, however, the character of the turbulence becomes progressively more homogeneous and isotropic (spatially uniform and independent of orientation).

The statistical behavior of turbulence once generated is described remarkably well by the idealized theory of homogeneous, isotropic turbulence (Batchelor 1967). This theory, which deals with the distribution of turbulent energy in eddies of different sizes, is expressed in terms of wavenumber, $k$ (in $\mathrm{m}^{-1}$ ), instead of length or size. The wavenumber of an eddy is just the inverse of its size, such that the wavenumber of the integral length scale of turbulence is $k_{1}=2 \pi / l$. The theory of isotropic, homogeneous turbulence is ex- pressed in terms of wavenumber because Fourier decomposition techniques that are central to the derivation of turbulent energy spectra are most easily expressed in terms of wavenumber At length scales smaller than 1 , or equivalently at wavenumbers greater than $k_{1}$, the theory predicts that the turbulent energy spectrum $E(k)$ (the wavenumber distribution of turbulent velocity variance, in $\mathrm{m}^{3} \mathrm{~s}^{-2}$ ) will be defined by a region known as the equilibrium range in which turbulent energy is transferred to successively smaller and smaller eddies (e.g. Landahl \& Mollo-Christensen 1986, and Fig. 1). In the equilibrium range, there is no direct external input of turbulent energy. The rate of energy transfer through this range equals the rate of energy extraction from the mean flow by the large
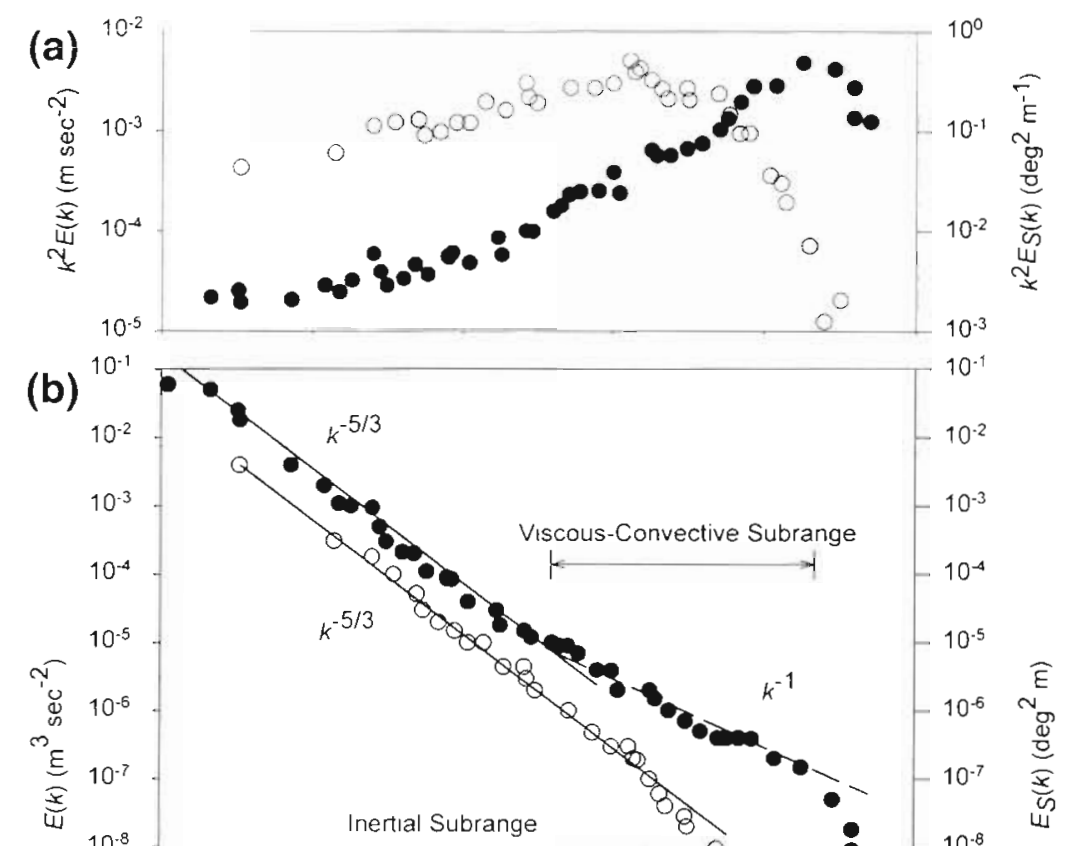

Fig. 1. Turbulence spectra observed by Grant et al. (1968) at a depth of $15 \mathrm{~m}$ near Vancouver Island, BC. Canada. Measurements were in the upper pycnocline under strong tidal forcing conditions; $\varepsilon=0.52 \mathrm{~cm}^{2} \mathrm{~s}^{-3}$ (a) Shear spectrum (O) and temperature gradient spectrum (O). (b) Velocity (O) and temperature (O) energy spectra. Adapted from Grant et al. (1968) by permission of Cambridge University Press 
eddies, which also equals the rate of energy dissipation by molecular viscosity at the smallest scales of turbulence.

Molecular viscosity transforms turbulent velocity shear into heat at the smallest scales of turbulence. The rate at which this occurs is known as the turbulent energy dissipation rate $\varepsilon$ (in $\mathrm{m}^{2} \mathrm{~s}^{-3}$ ). (Note that $\varepsilon$ frequently is given in different units. Conversion factors are listed in the legend of Table 1.) $\varepsilon$ is the product of (velocity shear) $^{2}$ and $v$ by definition. Velocity shear is the derivative of velocity with respect to distance, which, expressed in terms of wavenumbers, is equivalent to multiplying by $k$. Thus, $\varepsilon$ is given by

$$
\varepsilon=2 v \int_{0}^{\infty} k^{2} E(k) d k
$$

where $E(k)$ is the 3-dimensional total energy spectrum (Tennekes \& Lumley 1972). The quantity $k^{2} E(k)$ (in $\mathrm{m}$ $\mathrm{s}^{-2}$ ) is known as the dissipation spectrum or shear spectrum (Tatterson 1991).

The smallest scale of turbulence and the small size (high $k$ ) limit of the equilibrium range are defined by the Kolmogorov microscale,

$$
\eta=2 \pi\left(\frac{v^{3}}{\varepsilon}\right)^{\frac{1}{4}}
$$

(frequently measured in mm; Mann \& Lazier 1991, Denman 1994, Denman \& Gargett 1995). $\eta$ represents the point in a turbulent flow at which fluid inertia is no longer important. At sizes or separations smaller than $\eta$. fluid viscosity dominates and velocity shear is approximately the same at all scales, though it varies randomly in direction and strength (Lazier \& Mann 1989). Note that Eq. (6) is a factor of $2 \pi$ greater than the definition commonly used by engineers and physical oceanographers (e.g. Kundu 1990); Eq. (6) is used here because it is more common in the ecological literature. With $\eta$ defined as in Eq. (6), the Kolmogorov wavenumber may be defined as $k_{K}=2 \pi / \eta=\left(\varepsilon / v^{3}\right)^{1 / 4}$, which is the same as the definition of $k_{k}$ commonly used by engineers and physical oceanographers (who frequently leave the factor of $2 \pi$ out of the relationship between wavenumber and size). This distinction between different definitions of $\eta$ is important for aquatic ecologists because $\eta$ frequently is regarded as the actual size of the smallest turbulent eddies. Lazier \& Mann (1989) discuss this issue in depth and point out that the definition of $\eta$ favored by engineers and physical oceanographers is much smaller than any true turbulent eddy.

The range of wavenumbers such that $k_{l} \ll k \ll k_{k}$ is known as the inertial subrange (Fig. 1). It only exists if the Reynolds number of the turbulence $\left(R e_{l}=\right.$ $u_{R M S} l / v$ ) is large. The theory of homogeneous, isotropic turbulence predicts that the shape of the turbulent energy spectrum in the inertial subrange is given by

$$
E(k)=A_{2} \varepsilon^{\frac{2}{3}} k^{-\frac{2}{3}}
$$

where $A_{2}=1.5$ for $E(k)$ representing the 3 -dimensional total energy spectrum and $A_{2} \approx 0.5$ for the 1 -dimensional variance spectrum of a single velocity component (Tennekes \& Lumley 1972, Gross et al. 1994) Eq. (8) has been verified experimentally many times since its first convincing demonstration for an energetic tidal flow (Grant et al. 1962). It is one of the most important turbulence equations for aquatic ecology because it connects the large scales of turbulence responsible for large-scale mixing with the small scales of turbulence that influence interactions between small plankton. The shear spectrum $k^{2} E(k)$ increases as $k^{1 / 3}$ through the inertial subrange, reaching a maximum at approximately $0.1-0.2 k_{k}$ (Lazier \& Mann 1989 , and Fig. 1). The maximum in the shear spectrum corresponds to the high wavenumber limit of the inertial subrange, where viscosity begins to dissipate shear energy and the $-5 / 3$ slope of $E(k)$ becomes much more negative. Thus, large eddies at low wavenumbers dominate the turbulent energy spectrum (hence turbulent velocities), but small eddies at high wavenumbers dominate the turbulent shear spectrum (hence turbulent shear rates).

Turbulence also reduces large-scale gradients of scalars such as temperature, salinity, and nutrients through mixing by successively smaller eddies until molecular diffusivity can smooth out the gradients at the smallest scales. The theory of isotropic turbulence predicts that the slope of the scalar spectrum $E_{S}(k)$ (in [scalar units] ${ }^{2} m$ ) through the inertial subrange will be the same as the slope of the velocity spectrum $E(k)$, but it also predicts that $E_{S}(k)$ continues beyond the inertial subrange in water to a higher wavenumber diffusive cutoff (Fig 1). This additional region of the scalar spectrum is known as the viscous-convective subrange, and it has a slope proportional to $k^{-1}$ (Tennekes \& Lumley 1972, Kundu 1990). The break in $E_{5}(k)$ occurs at a higher wavenumber than the break in $E(k)$ because molecular diffusivity is not as effective at dissipating scalar gradients as molecular viscosity is at dissipating velocity gradients in water

The smallest size for scalar fluctuations is known as the Batchelor microscale,

$$
\eta_{S}=2 \pi\left(\frac{v D_{S}^{2}}{\varepsilon}\right)^{\frac{1}{4}}=\eta\left(\frac{v}{D_{S}}\right)^{-\frac{1}{2}}
$$

(Mann \& Lazier 1991), where $D_{S}$ is the molecular diffusivity of the scalar (in $\mathrm{m}^{2} \mathrm{~s}^{-1}$ ). In water, the ratio $\mathrm{v} / D_{S}$ (the Prandtl number for heat and Schmidt number for everything else) usually is quite large, such that $\eta_{\mathrm{S}} \ll$ $\eta$. The scalar gradient spectrum defined by $k^{2} E_{S}(k)$ reaches a maximum at the break in slope of $E_{S}(k)$ that corresponds to the upper limit of the viscous-convec- 


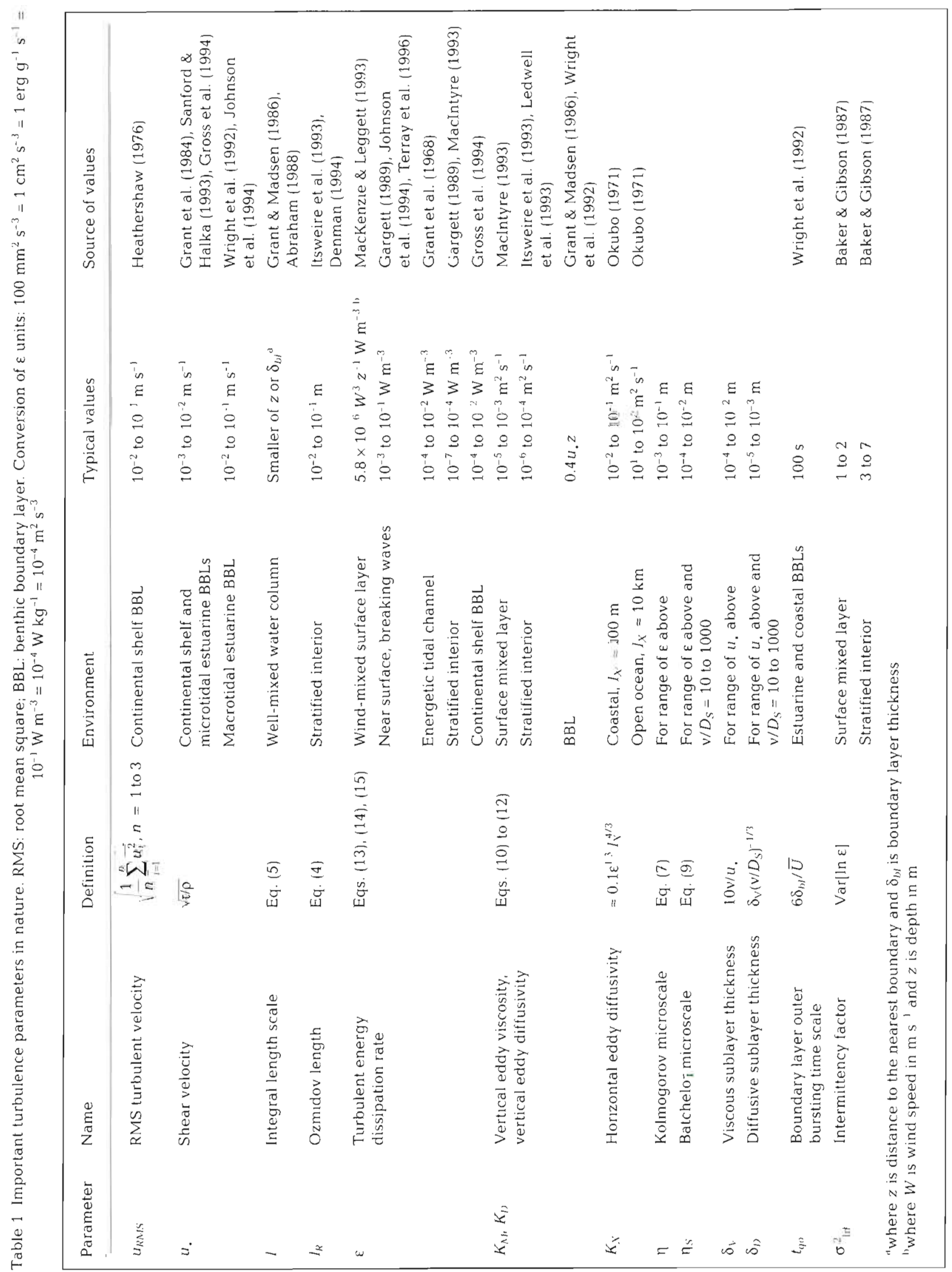


tive subrange, at approximately $0.1 k_{S}=0.1\left(2 \pi / \eta_{S}\right)$. This means that sharp changes in scalar concentration can occur across distances similar to the Kolmogorov microscale (Fig. 1), which may have important consequences for the micro-environment of small plankton.

\section{Turbulent mixing}

Effective mixing of mass and momentum is one of the most important consequences of turbulence. Most of this mixing is accomplished by the stirring action of large, energetic eddies (Okubo 1980, Garrett 1989, Kundu 1990). Since these eddies are dependent on the nature of the large-scale flow, it follows that turbulent mixing is a property of the flow and not of the fluid. The simplest parameterization of turbulent mixing of momentum (i.e. turbulent stress) is to assume that turbulence results in a much larger effective coefficient of viscosity, the eddy viscosity $K_{M}$ (in $\left.\mathrm{m}^{2} \mathrm{~s}^{-1}\right)$. For example, the vertical shear stress, $\tau$ (in $\mathrm{kg} \mathrm{m}^{-1} \mathrm{~s}^{-2}$ ), in a horizontally homogeneous, unidirectional flow may be written:

$$
\tau(z, t)=\rho K_{M}(z, t) \frac{\partial u(z, t)}{\partial z}
$$

where $\tau, K_{M}$, and $u$ have been written as functions of the vertical direction $z$ and time $t$ to emphasize that spatial and temporal variability of all three is the most general case, and the partial derivative symbol $\partial$ has been used to emphasize the multi-dimensionality of the problem. The equivalent parameterization of turbulent diffusion of mass is

$$
F_{S}(z, t)=K_{D}(z, t) \frac{\partial C_{S}(z, t)}{\partial z}
$$

where $F_{S}$ is the flux of the scalar in the $z$ direction (in scalar mass $\left.\mathrm{m}^{-2} \mathrm{~s}^{-1}\right), K_{D}$ is the coefficient of eddy diffusivity (in $\mathrm{m}^{2} \mathrm{~s}^{-1}$ ), and $c_{5}$ is the concentration of the scalar (in scalar mass $\mathrm{m}^{-3}$ ).

For practical purposes it often is assumed that $K_{D} \approx$ $K_{M}$, which is called the Reynolds analogy (e.g Kundu 1990). In a well-mixed water column the Reynolds analogy is quite reasonable, but it is no longer valid in the presence of stable density stratification (Turner 1973). Stable stratification decreases turbulent mixing in general, but mixing of mass decreases more than mixing of momentum such that $K_{D}$ can be significantly smaller than $K_{M}$ (e.g. Abraham 1988, Lehfeldt \& Bloss 1988, Chao \& Paluszkiewicz 1991)

A common and convenient assumption about $K_{M}$ and $K_{D}$ is that they are constant. Under this assumption, all of the considerable and relatively familiar mathematics of molecular diffusion (Crank 1975) may be applied directly to turbulent diffusion as well, simply substituting a much larger value of viscosity or dif- fusivity. The constant eddy viscosity/diffusivity often is written as proportional to the product of a characteristic turbulent velocity and the integral length scale of the turbulence, or

$$
K_{D}, K_{M} \propto u_{R M S} l \text { or } K_{D}, K_{M} \propto u . l
$$

(Kundu 1990) where $u .=(\tau / \rho)^{0.5}\left(\right.$ in $\left.\mathrm{m} \mathrm{s}^{-1}\right)$ is the shear velocity (the usual scale velocity for boundary layer turbulence). The constant of proportionality implied in Eq. (12) is approximately 1, with its exact value depending on the details of each situation. However, Taylor's theory of turbulent dispersion (e.g. Csanady 1973, Kundu 1990) demonstrates that assuming a constant eddy viscosity/diffusivity is valid only when the length and time scales of interest are larger than the integral length and time scales of the turbulence. When this is not the case the eddy viscosity/diffusivity may vary with time, with distance away from a boundary (which gives the familiar logarithmic boundary layer profile; e.g. Grant \& Madsen 1986), or with the size of a dispersing patch [which gives a characteristic

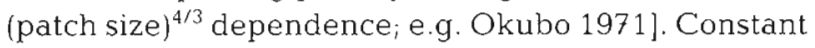
$K_{M}$ and $K_{D}$ are assumed in the remainder of this paper for discussions of scaling, but the limitations of this assumption should be kept in mind.

\section{Spatial and temporal variability of turbulence}

Landahl \& Mollo-Christensen (1986) point out that characterizing a variable flow only by its spectra or average properties presents a limited description of the true nature of the flow. Temporal and spatial variability are lost in the averaging process. Several important properties of turbulence tend to be temporally and spatially variable. Often the flows that generate turbulence are variable in time and space as well, which can result in variable mixing on a larger scale.

Turbulence is intermittent. This intermittency takes 2 forms, both of which may be related to the probability distribution of turbulent quantities. In homogeneous, isotropic, steady turbulence, velocity fluctuations are approximately normally distributed but spatial and temporal derivatives of the velocity are not. Batchelor (1967) points out that small-scale shear in homogeneous turbulence tends to be intermittent, characterized by a higher than normal kurtosis (4th moment) of its probability distribution that corresponds to relatively infrequent bursts of high shear energy. This means that the dissipation rate (the square of the shear) is intermittent even when there is no spatial or temporal variability of the turbulence. Dissipation rate also tends to be lognormally distributed (Baker \& Gibson 1987, Yamazaki \& Osborn 1988), which implies a mean that is greater than the most 
probable value and a higher than normal probability of very large events.

The second form of intermittency is associated with turbulent flows that are not homogeneous or steady. A dimensionless intermittency factor, $\gamma$, is defined as the fraction of time that the flow at a point is turbulent (e.g. Townsend 1976, Kundu 1990). At the center of a turbulent wake $\gamma=1$, but it decreases towards the edge of the average envelope of the wake as turbulent eddies become more and more infrequent, until $\gamma=0$ outside the limit of turbulent activity. This form of variability accentuates the skewness ( $3 \mathrm{rd}$ moment) of the probability distribution of dissipation, causing it to deviate from lognormality (Yamazaki \& Lueck 1990). Most natural flows are variable in this second sense, including steady shear flows (Townsend 1976, Landahl \& MolloChristensen 1986), stratified turbulent flows (Yamazaki \& Osborn 1988, Fernando 1991, Gibson 1991), and complicated, time varying combinations of the two (Dyer \& New 1986).

Strong spatial gradients of turbulence frequently are associated with turbulence generation. For example, the length scale for turbulence generated by shear at a boundary increases with distance away from the boundary, $z$, while turbulence dissipation rate decreases as $z^{-1}$ (Grant \& Madsen 1986). In smooth turbulent boundary layer flow, a thin viscous sublayer next to the boundary acts essentially in the same capacity as in free turbulence, and a thinner diffusive sublayer acts similarly to $\eta_{s}$ (Dade 1993). Fig. 2a illustrates the sharp gradients in turbulent dissipation rate

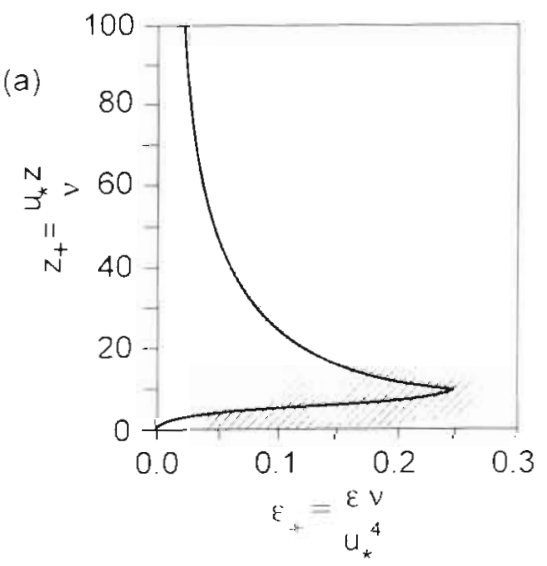

(b)

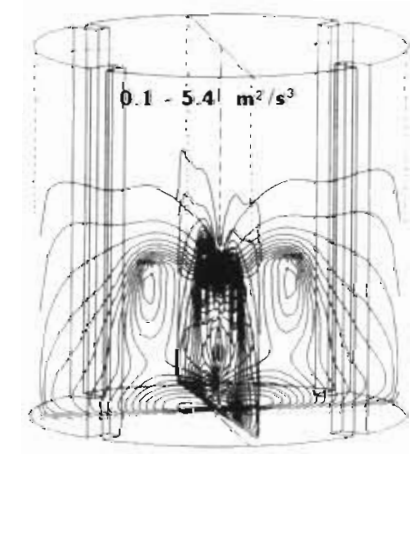

Fig. 2. Distribution of turbulent dissipation rate $\varepsilon$ in (a) a boundary layer and (b) near an impeller (a) Near the wall in a smooth turbulent boundary layer; from Dade (1993) by permission of the American Society of Limnology and Oceanography, Inc. Solid line is modeled curve, gray area represents scatter of data summarized by Patel et al. (1985). (b) In a standard geometry mixing tank with an A410 axial impeller at a Reynolds number of $2 \times 10^{5}$, from Weetman (1992) with kind permission from Kluwer Academic Publishers. Numbers refer to the total range of $\varepsilon$. Model contours show that $\varepsilon$ is large near the position of the impeller (not shown) and immediately below at the bottom, but that it decreases rapidly with both axial and radial distance near the wall in a smooth turbulent boundary layer. Similar gradients are present in the wind-mixed surface layer (Mackenzie \& Leggett 1993), though nearsurface gradients in dissipation may be even steeper during periods of high wind and breaking waves (Gargett 1989, Terray et al. 1996). Localized regions of higher turbulence intensity near step-like density interfaces also have been identified in what might otherwise be thought of as continuous stratification (Macintyre et al. 1995).

\section{Measurements of natural turbulence}

Turbulence in natural water bodies is measured using 1 of 3 broad classes of techniques. These techniques tend to be limited to different subregions of the environment for practical reasons, though some of the limitations are disappearing as technologies improve. First, time series of rapidly sampled, small-scale velocity at a fixed point in a flow are used to determine mean and turbulent contributions to the total velocity field. Often these Eulerian measurements are conducted in the bottom boundary layer (Gross \& Nowell 983, Grant et al. 1984, Williams et al. 1987) or the sur(Agrawal et al. 1992) with the sensors attached to a rigid, stationary platform. Because most theory deals with length rather than time, the time series of turbulent velocity are converted to space series by dividing by the time-averaged velocity, invoking Taylor's 'frozen turbulence' hypothesis (Tennekes \& Lumley 1972, Landahl \& Mollo-Christensen 1986, Kundu 1990). Second, nearly instantaneous space series of turbulent velocity or temperature fluctuations are measured with profiling microstructure instruments (Grant et al. 1968, Itsweire \& Osborn 1988, Haury et al. 1990, Macintyre 1993). More often than not, these measurements are conducted in the interior of the water column away from the immediate vicinity of either boundary. An interesting variation on this technique has been proposed by Galbraith \& Kelley (1996), who suggest that internal mixing may be estimated by identifying unstable density profiles using a standard CTD. Third, some kind of conservative tracer is injected or placed at known locations or depths and its distribution followed through time to estimate mixing directly. Neutrally buoyant dyes are used for both lateral 
dispersion (Okubo 1971) and vertical diffusion studies (Ledwell et al. 1993), while isopycnal drifters (Richardson 1993) and surface drogues (Davis 1985, List et al. 1990) are used primarily to estimate horizontal dispersion and transport.

Several techniques are available for estimating $\varepsilon$ from turbulence measurements. $\varepsilon$ may be estimated in terms of the large scale turbulence characteristics by

$$
\varepsilon=A_{1} \frac{u_{R M S}^{3}}{l}
$$

where $A_{1}$ is a nondimensional constant of order 1 (Kundu 1990, Moum 1996). The integral length scale, l, of natural turbulence is sometimes measured (MacIntyre 1993), but the assumption that it behaves as in laboratory experiments often yields good results as well. For example, in laboratory experiments on turbulent boundary layers, $l \approx z$ and $u_{R M S} \approx u$., such that Eq. (13) becomes

$$
\varepsilon=\frac{u_{.}^{3}}{\kappa z}
$$

where $\kappa=0.4$ is von Karman's constant. This relationship has been found to give reasonable agreement with field data (Grant et al. 1984, Gross et al. 1994). Microstructure investigators usually calculate $\varepsilon$ as the variance of a single component of shear:

$$
\varepsilon=7.5 v\left(\frac{\mathrm{d} u}{\mathrm{~d} z}\right)^{2}
$$

(SCOR Working Group 69 1988, Yamazaki \& Osborn 1990), where $u$ is a velocity component transverse to the direction of motion $z$ of a microstructure profiler. Finally, a number of investigators have calculated $\varepsilon$ by fitting Eq. (8) to observed velocity spectra (Grant et al. 1984, Agrawal et al. 1992, Gross et al. 1994, Terray et al. 1996)

Several techniques also are available for estimating the effective turbulent diffusion coefficient in nature. When tracers are used, estimates of $K_{D}$ are obtained by fitting theoretical curves to observed data (e.g. Kent \& Pritchard 1959, Ledwell et al. 1993). Another technique for estimating spatially and temporally variable dispersion is through seeding of numerical models with simulated Lagrangian tracers, then following the statistical behavior of the ensemble as the numerical flow field evolves (Geyer \& Signell 1992). Further, turbulence microstructure investigators frequently estimate $K_{D}$ based on measurements of energy dissipation, according to

$$
K_{D} \approx 0.2 \frac{\varepsilon}{N^{2}}
$$

(Osborn 1980, Itsweire et al. 1993). A large body of literature treating turbulent diffusion in the environment also has developed in response to modeling and engineering needs (Csanady 1973, Fischer et al. 1979) and takes the practical approach of assuming some functional form for $K_{D}$ and setting controlling parameters empirically. Relationships of the form of Eq. (12) are used frequently (e.g. Middleton et al. 1993).

\section{Summary}

Natural aquatic turbulence is generated at the largest scales of motion and dissipated at the smallest scales. Large-scale velocity gradients and unstable buoyancy fluxes are the source of most turbulent energy. However, velocity and scalar gradients are most intense at the smallest scales of turbulent motion. The large and small scales of turbulence are connected by the well-established theory of isotropic, homogeneous turbulence, which allows large-scale mixing to be estimated from small-scale parameters (Eq. 16) and small scale dissipation to be estimated from large-scale parameters (Eq. 13) under some conditions. Mixing of mass is very similar to mixing of momentum at intermediate scales, but it is less effective at large scales in the presence of stable stratification and it is less effective at the smallest scales of turbulence. Turbulence is variable in both time and space. Dissipation rate is intermittent, with infrequent, large events. The largescale flows that generate turbulence also vary in time and space. Large gradients in turbulent energy and length scales are common, particularly near boundaries.

Table 1 summarizes the parameters identified in this section and gives approximate ranges for their values in different parts of the natural aquatic environment. It is clear that there is no single parameter that completely characterizes turbulence. It is not yet clear, however, which parameters or combinations of parameters best characterize turbulent mixing and its effects in experimental ecosystems. This is the subject of the next section.

\section{IMPORTANT TURBULENCE SCALES FOR ECOSYSTEM STUDIES}

One approach to evaluating the effects of turbulent mixing in aquatic ecosystems is to express these effects in terms of times, lengths, and velocities, which enables straightforward comparison to many ecosystem parameters. This approach is adopted here in an attempt to condense the numerous natural turbulence parameters discussed in the previous section into a meaningful and usable set of turbulence parameters for experimental ecosystem studies. Issues of spatial/ 
temporal variability and benthic-pelagic coupling also are considered.

\section{Large-scale mixing - the mixing time}

Mixing time is the amount of time that it takes for a conservative tracer injected at some point in a region to mix to some degree of uniformity across that region. This may seem like a vague definition, but in fact the precise definition of a mixing time depends on the location of the injection point, the degree of uniformity that is considered 'mixed', and the boundary conditions of the region of interest. The most frequent expression given for the mixing time in a diffusiondominated environment is

$$
T_{m}=\frac{L^{2}}{2 K_{D}}
$$

(Nixon et al. 1979, Lewis et al. 1984a, MacIntyre 1993), where $T_{m}$ is the mixing time (in s), $L$ is the size of the region of interest (e.g. depth in $\mathrm{m}$ ), and $K_{D}$ is the eddy diffusivity (in $\mathrm{m}^{2} \mathrm{~s}^{-1}$ ). Eq. (17) corresponds to the time for a tracer injected at one boundary of a region to become $97 \%$ uniform within that region, when the boundaries are perfectly reflecting (by solution of Eq. 2.17 in Crank 1975). This is a good model for an experimental ecosystem enclosure. If the injection point is located in the interior of the region of interest, then the mixing time to the same degree of uniformity is controlled by the furthest distance to a boundary. For example, if the injection point is in the center of the region then the mixing time is given by

$$
T_{m}=\frac{(L / 2)^{2}}{2 K_{D}}=\frac{L^{2}}{8 K_{D}} .
$$

(e.g. MacIntyre 1993). If the boundaries are open, Eq. (18) corresponds to central injection and a Gaussian concentration profile with $\sigma=L / 2$ at $t=T_{m}$, such that the tracer is $62 \%$ uniform across a region of size $L$ at $t=T_{m}$ (Csanady 1973).

$T_{m}$ is an excellent choice for the single parameter that best expresses the influence of large scale mixing in ecology. Many ecological parameters associated with large scale distribution or dispersal may be expressed as ratios of $T_{m}$ to characteristic ecosystem times. The most appropriate definition depends on the problem of interest, but generally the boundary mixing time (Eq. 17) is best for boundary flux problems and the central mixing time (Eq. 18) is best for internal dispersion problems. The ratio of the central mixing time (Eq. 18) to the turnover time of a plankton population, $T_{g}=1 / r$ where $r$ is the growth rate (in $\mathrm{s}^{-1}$ ), is

$$
\frac{T_{m}}{T_{g}}=\frac{L^{2}}{8 K_{D} \frac{1}{r}}=\frac{\pi^{2}}{8} \frac{L^{2}}{\left(\frac{\pi K_{D}}{r}\right)^{2}}=1.2\left(\frac{L}{L_{c}}\right)^{2}
$$

where $L_{\mathrm{r}}=\pi\left(K_{D} / r\right)^{1 / 2}$ is the Kierstead-Slobodkin critical patch size (in $m_{\text {; }}$ Okubo 1980, Platt 1981). If $T_{m}>$ $T_{g}$, patches develop inside the region and if $T_{m}<T_{g}$. patches disperse. The ratio of the boundary mixing time (Eq. 17) in a water column of depth $h$ to the settling time, $T_{s}=h / W_{s}$, (in s) for a particle with fall velocity $w_{s}\left(\right.$ in $\left.\mathrm{m} \mathrm{s}^{-1}\right)$ is

$$
\frac{T_{m}}{T_{s}}=\frac{h^{2}}{2 K_{D}} \frac{w_{s}}{h}=\frac{1}{2}\left(\frac{w_{s} \underline{h}}{K_{D}}\right)=\frac{1}{2} R_{h}
$$

The parameter $R_{h}$ is a full-depth Rouse number (for a discussion of the Rouse number see, e.g., Muschenheim 1987). For large $R_{h}\left(T_{m}>T_{s}\right)$, settling particles tend to be concentrated near the bottom; for small $R_{h}$ $\left(T_{m}<T_{s}\right)$, particles tend to be dispersed throughout the water column. This argument is equally valid for buoyant particles, except that accumulation tends to occur near the surface rather than the bottom. Lewis et al. $(1984 \mathrm{a}, \mathrm{b})$ also discuss the ratio of the boundary mixing time to the photoadaptation period of phytoplankton, which, along with the ratio of the mixed layer depth to the depth of the euphotic zone, controls the photosynthetic performance of algae in the surface layer. Finally, the ratio of horizontal mixing time to the duration of larval dispersal should influence the uniformity of dispersal within a region of interest (Okubo 1980).

\section{Mass fluxes and mass transfer coefficients}

One of the most important aspects of turbulent mixing in ecology is its influence on fluxes of nutrients and wastes to and from different ecosystem compartments. This influence is expressed through flow control of mass transfer processes, and it is most important when it limits fluxes relative to biogeochemical supply or demand. Most often the limiting fluxes are those that occur across boundaries: the air-sea interface (Jaehne et al. 1987), the sediment-water interface (Jørgensen \& Revsbech 1985, Santschi et al. 1991, Dade 1993, Glud et al. 1995), the pycnocline (Denman \& Gargett 1995), surfaces of attached organisms (Koch 1994), surfaces of planktonic organisms (Mann \& Lazier 1991, Karp-Boss et al. 1996), surfaces of detrital aggregates (Alldredge \& Cohen 1987), and walls of experimental ecosystem enclosures (Oviatt 1994). Boundaries restrict turbulent length scales and velocities and hence restrict the magnitude of the eddy diffusivity, such that mixing can become slow enough to limit fluxes. In general, flux limitation is not an issue within the interior of compartments such as the sur- 
face mixed layer and the bottom mixed layer, unless turbulent mixing is very weak.

Assumption of a constant eddy diffusivity allows all of the fluxes of interest to be written using the formalism of Fick's law:

$$
F_{S}=\left(D_{S}, K_{D}\right) \frac{\mathrm{d} c_{S}}{\mathrm{~d} z} \approx\left(D_{S}, K_{D}\right) \frac{\Delta c_{S}}{\Delta z}=\beta \Delta c_{S}
$$

where either $K_{D}$ (the turbulent eddy diffusivity in $\mathrm{m}^{2}$ $\mathrm{s}^{-1}$ ) or $D_{s}$ (the molecular diffusivity in $\mathrm{m}^{2} \mathrm{~s}^{-1}$ ) are used. depending on the scale of the problem, $c_{S}$ is the concentration of the scalar quantity of interest (in mass $\left.\mathrm{m}^{-3}\right), z$ is distance in the direction of the maximum gradient (taken as positive upward for simplicity, in $m$ ), and $\Delta c_{S}$ refers to the change in $c_{S}$ across the diffusionlimiting layer thickness $\Delta z$. $\beta$ is known as the mass transfer coefficient, with units of velocity $\left(\mathrm{m} \mathrm{s}^{-1}\right.$; Santschi et al. 1991, Patterson 1992, Dade 1993). Eq. (21) provides a convenient way to think about factors influencing fluxes; $\beta$ is determined by flow conditions while $\Delta c_{S}$ is determined by the biological or chemical processes of interest.

At small scales, $\beta=D_{S} / \Delta z$. Since diffusion is entirely molecular, flow control of $\beta$ occurs only through changes in $\Delta z$; i.e. factors that decrease the thickness of the diffusion-limiting layer increase the mass transfer velocity. Decreasing $\Delta z$ can occur through increases in flow speed or roughness at a solid surface (Dade 1993), through the development of waves at the air-water interface (Jaehne et al. 1987), through relative velocities induced by swimming or sinking of larger plankton (Mann \& Lazier 1991, Kiorboe 1993), or in a general sense through anything that increases the Reynolds numbers of organisms (Patterson 1992, Karp-Boss et al. 1996). In all turbulent flow cases, $\Delta z$ is proportional to $\varepsilon^{-1 / 4}$ (see Eq. 9), where $\varepsilon$ is the turbulent energy dissipation rate near the outer edge of the diffusion-limiting layer

Spatial variability in $\varepsilon$ can lead to problems with scaling boundary fluxes in experimental enclosures. When turbulence is generated at a boundary, the dissipation rate is highest near the boundary and decays rapidly away from it (Eq. 14 and Fig. 2a); this is the most common situation in nature, where the surface and bottom boundary layers are important turbulence generation sites. When turbulence is generated away from the boundary and impinges upon it, the dissipation rate is low near the boundary and increases away from it (Fig. 2b and Brumley \& Jirka 1987); this is the most common situation in an experimental ecosystem enclosure. The volume-averaged level of turbulent energy needed to achieve the same boundary mass transfer rate is different in these 2 cases. Thus, it is possible to stir a benthic flux chamber so as to mimic realistic values of $\beta$ at the sediment-water interface (Buchholtz-ten Brink et al. 1989, Glud et al. 1995), but the average level of turbulent energy inside the benthic chamber is likely to be unrealistically high. Similarly, a realistic level of turbulent energy in an experimental enclosure may result in unrealistically low boundary fluxes.

At large scales, $\beta=K_{D} / \Delta z$. In this case, both the limiting-layer thickness and the turbulent diffusivity are affected by the flow. The best example of this mode of flow control is mixing across a pycnocline, which differs depending on the source of turbulent energy (Turner 1973, Abraham 1988, Fernando 1991). Internal mixing is generated by velocity shear within the pycnocline, depending on the Richardson number of the flow (Eq. 2). As pointed out previously, internal mixing dominates vertical mixing across ocean thermoclines. External mixing is generated by turbulence above or below a pycnocline. This form of mixing occurs in nature at the base of the surface mixed layer and at the top of the bottom mixed layer, but it is virtually the only form of mixing possible in an artificial enclosure where there is no large-scale velocity shear to generate internal mixing. Internal mixing tends to weaken the density gradient by entraining fluid from outside the pycnocline into the pycnocline, and it results in a turbulent diffusivity given by Eq. (16). External mixing tends to sharpen the density gradient. If mixing is on one side of the pycnocline only, then the mixed layer entrains the unmixed layer at a rate known as the entrainment velocity, which is identical to $\beta$ (Fernando 1991). If both sides of the pycnocline are mixed, then fluid is exchanged across the pycnocline in both directions at the respective, independent entrainment velocities (Turner 1973). Both internal and external mixing result in mass fluxes across a pycnocline, but the sources of mixing energy are different, the consequences of mixing are different, and the magnitudes of $\beta$ are different.

In many cases, a mass transfer coefficient may be converted to a mass transfer rate for comparison to biogeochemical rates of uptake or release. This is particularly convenient in experimental ecosystem enclosures. Given a mass transfer coefficient $\beta$ across a boundary with surface area $A\left(\mathrm{in}^{2}\right)$ into a volume $V$ (in $\mathrm{m}^{3}$ ), the mass transfer rate, $m\left(\right.$ in $\mathrm{s}^{-1}$ ), is given by

$$
m=\frac{\beta A}{V}
$$

If $m$ is compared to some biological or geochemical rate of uptake or release, $r$ (in $\mathrm{s}^{-1}$ ), the potential for mass transfer limitation may be evaluated readily. For example, if $r$ represents the maximum nitrate uptake rate by surface layer phytoplankton and $m$ represents the mass transfer rate of nitrate across the pycnocline, then $m / r<1$ indicates that pycnocline fluxes of ammonium may be limiting phytoplankton growth.

It is important to recognize that similar profiles of temperature, salinity, nutrients, etc. may be main- 
tained with different rates of mass transfer. For example, Donaghay \& Klos (1985) maintained stratified water columns in the MERL mesocosms at the University of Rhode Island, USA, by chilling the lower layer and relying on solar heating to maintain a warm upper layer. Mixing was maintained at a constant rate in both the upper and lower layers. The temperature profile that they achieved represented a balance between the rate of mixing (which controlled $m$ ) and the rate of heat loss in the lower layer (essentially the same as $r$ ). A steady-state profile was established for $m=r$. A similar profile could have been maintained with less chilling and less mixing, or with more chilling and more mixing. The resultant rates of mass transfer across the thermocline in these alternative scenarios would have been quite different, however. In a similar vein, Boyce (1974) demonstrated that similarity in temperature profiles inside and outside a thin-wall limnocorral could be achicved easily despite gross dissimilarities between the vertical mixing processes inside and outside, simply by efficient horizontal heat transfer.

A general conclusion from these considerations of mass transfer is that simulation of both realistic water column turbulence and realistic boundary mass fluxes is a daunting task in an experimental ecosystem. The primary reason that it is so difficult is that turbulence in nature tends to be generated by shear at the surface and bottom boundaries or within the pycnocline, while mixing in an experimental ecosystem usually is generated by artificial internal mechanisms such as paddles, grids, air bubbling, or pumping. Since mass transfer rates depend on the source of mixing energy, it is difficult to simulate natural mass fluxes in an artificial enclosure without distorting the total mixing energy. Natural surface mass fluxes generated by convective overturning on a windless night may be simulated in a captured water column, but this is an exception rather than a rule.

\section{Small-scale effects of turbulence}

Recent research has indicated that turbulence may have as profound an ecological effect at small scales as it does at large scales, over and above its effects on mass transfer. There are 4 inter-related areas in which turbulence affects small-scale ecosystem processes: predator-prey interactions, particle aggregation and disaggregation, small-scale patchiness, and speciesspecific growth inhibition.

The influence of small-scale turbulence on planktonic predator-prey interactions has received a great deal of attention in recent years. Much of this attention stems from the work of Rothschild \& Osborn (1988), who proposed an enhanced rate of predator-prey con- tact due to small-scale turbulent shear. The expression for relative turbulent velocity between 2 particles separated by a distance, $r$, that they used was

$$
u_{r}=1.9(\varepsilon r)^{\frac{1}{3}}
$$

which strictly speaking is valid within the inertial subrange. Hill et al. (1992) showed that an equation of this form governs particle-particle relative velocities even at separations smaller than the Kolmogorov microscale (although they quote a factor of 1.37 rather than 1.9 ), most probably because particles do not exactly follow the flow. Extension of Eq. (23) to sub-Kolmogorov scales is important because the organisms most likely to be affected by turbulence-enhanced contact are similar to or smaller than $\eta$ in size (Dower et al. 1997).

Much has been written about the positive influences of turbulence on predator-prey contact and the possible negative influences of turbulence on organism behavior since Rothschild \& Osborn's seminal work (Sundby \& Fossum 1990, Saiz et al. 1992, Alcaraz et al. 1994, Muelbert et al. 1994, Peters \& Gross 1994, Denman \& Gargett 1995, Landry et al. 1995, Dower et al. 1997). Some of this research suggests that these small-scale processes may influence directly large-scale abundances and distributions (e.g. Sundby \& Fossum 1990, Muelbert et al. 1994). However, in a series of comments on turbulence and predator-prey interactions, Browman (1996) and others describe this particular area of research. as theory-rich but data-poor, in need of both field and laboratory verification. Dower et al. (1997) also caution that more research is needed before links between small-scale turbulence and large-scale population dynamics can be established firmly.

Small-scale turbulence also influences particle aggregation and disaggregation processes through its influence on particle-particle contact and small-scale shear. Aggregate size and excess density are the primary determinants of settling rate (van Leussen 1988, Jumars 1993, Fennessy et al. 1994). Aggregation and disaggregation processes influence settling of phytoplankton blooms (Kiørboe et al. 1990, Kiørboe 1993), characteristics and vertical distributions of marine snow (MacIntyre et al. 1995), and settling and deposition of cohesive sediment particles in the bottom boundary layer (van Leussen 1988, 1997, Wolanski et al. 1992). van Leussen $(1988,1997)$ argues that the Kolmogorov microscale sets an effective upper limit on aggregate size, demonstrating how turbulence can both promote and limit aggregation.

An intriguing aspect of small-scale turbulence is that it may promote small-scale patchiness rather than uniformity. Instantaneous gradients of scalars such as heat, salt, and nutrients are greatest at scales similar to $\eta$ (as discussed previously). Physically this may be attributed to the tendency of small-scale shear, which 
is no longer truly turbulent, to create elongated concentration streaks that eventually become narrow enough to be affected by molecular diffusion (Garrett 1989). Microscale patchiness of odor plumes under turbulent forcing has been observed in the laboratory (Moore et al. 1992). Although the mechanism is slightly different, Squires \& Yamazaki (1995) also have modeled preferential concentration of particles by smallscale turbulence, with possible local concentrations up to 40 times the volume-averaged concentration.

Small-scale shear similar to that produced by turbulence has been shown to inhibit the growth of certain dinoflagellate species (Thomas \& Gibson 1992, Gibson \& Thomas 1995), presumably due to physiological stress. Shear thresholds for decreased or inhibited growth are species specific. It appears that relatively short exposure to high shear can be just as damaging as more continuous exposure. Turbulence also has been shown to alter the structure of bacterioplankton communities (Moeseneder \& Herndl 1995). The small scale shear that acts on organisms much smaller than $\eta$ is proportional to $(\varepsilon / v)^{1 / 2}$, rather than $\varepsilon^{1 / 3}$ as in Eq. (23) (Hill et al. 1992).

The common thread of all of these small-scale effects of turbulence is that they depend on turbulence dissipation rate $\varepsilon$ raised to some fractional power, in addition to depending on properties of the fluid medium or particles. Prcdator-prey interaction and particle aggregation depend on $\varepsilon^{1 / 3}$ as long as Eq. (23) is valid. Particle disaggregation depends on velocity shear relative to aggregate strength, with typical maximum aggregate sizes similar to $\eta$, which in turn depends on $\varepsilon^{-1 / 4}$. Velocity shear depends on $\varepsilon^{1 / 3}$ at scales much larger than $\eta$ and on $\varepsilon^{1 / 2}$ at scales much smaller than $\eta$. Small scale patchiness depends on the existence of a significant viscous-convective subrange in the scalar energy spectrum, which in turn depends on $\varepsilon^{-1 / 4}$ and on the ratio of molecular viscosity to molecular diffusivity (the Schmidt number).

\section{Spatial and temporal variability of turbulence}

Spatial and temporal variability of turbulence can have important consequences for ecosystem processes. At small scales, Gibson \& Thomas (1995) reported that brief daily exposure to high turbulent shear is enough to inhibit the growth of dinoflagellates. Hwang et al. (1994) showed that, though copepods exhibit initial escape responses to turbulent shear, they eventually become habituated to the extra stimulus. The length of the calm interval between bursts of turbulent shear determines how long habituation is maintained. Bowen et al. (1993) showed that motile bacteria may be capable of temporary clustering in the vicinity of phytoplankton, with increased clustering during the periods of calm between intermittent bursts of turbulent shear

Variability of larger-scale turbulent mixing is important as well. Alternating mixing and stratification is necessary for initiation of phytoplankton blooms (Legendre 1981, Koseff et al. 1993, Taylor \& Stephens 1993). Kiorboe (1993) argued that frequent periods of alternating mixing and stratification give a competitive advantage to diatoms relative to smaller phytoplankton, whereas long periods of stratification with little mixing promote the opposite trend. Lasker (1981) suggested that periods of stable, non-turbulent conditions were needed to avoid over-dilution of larval anchovy food supplies by turbulent mixing. Lewis et al. (1984a, b) and Schubert et al. (1995) showed how variable light exposure of phytoplankton caused by large-scale vertical mixing in and out of the euphotic zone can control photosynthetic performance. Eckman et al. (1994) indicated that the tidal variabilities of turbulent bottom shear stress and vertical mixing should be important determinants of the settlement success of benthic larvae in shallow water.

Difficulties arise in attempting to identify meaningful measures of turbulence variability for ecosystem studies. The problem is simplified somewhat by separating considerations of variability into those that primarily affect small scales and those that primarily affect large scales. Turbulent shear and dissipation rate, which are most important at small scales, are characterized by infrequent large events and intermittency. Reasonable measures of this kind of turbulence variability in an experimental ecosystem might include the range of turbulent dissipation rates likely to be encountered by an organism and the characteristic time scale of intermittence. Baker \& Gibson (1987) advocated use of the variance of the logarithm of dissipation rate as a measure of intermittency. In the present context this parameter is more like a measure of the range of dissipation rates, but it is a good parameter to measure because it may be compared to data obtained in natural flows. Temporal variability of large-scale mixing may be characterized by the time history of a large scale turbulence parameter such as $u_{R M S}, T_{m}$, or $K_{M}$. Appropriate measures in experimental ecosystems might include on and off times for mixing and the phase of the mixing cycle relative to other important cycles of external forcing, such as the light-dark cycle.

Finally, it must be remembered that turbulence at large and small scales generally covaries. Thus, high winds that increase predator-prey contact rates in near-surface waters also disperse prey patches and potentially lower prey concentrations (Dower et al. 1997). Similarly, plankton that are advected through zones of high and low turbulent energy by large eddies 
in nature experience considerably greater variation in small-scale shear than plankton held in an experimental chamber with a continuously oscillating grid.

\section{Benthic-pelagic coupling}

It is tempting to consider pelagic and benthic processes in isolation. For example, SCOR Working Group 85 (1990) concentrated separately on free-floating open-water enclosures and sublittoral benthic enclosures. However, many of the problems that they identified as appropriate for investigation in experimental ecosystems are affected directly by benthic-pelagic coupling. Artifacts resulting from separation of the water column and the benthos especially are likely in shallow water ecosystems. Oviatt (1994) notes major differences in plankton communities in the MERL mesocosms that resulted from inclusion or exclusion of a realistic benthos; both benthic nutrient remineralization and pelagic-benthic competition were implicated. Threlkeld (1994) also presents cogent arguments for pursuing experiments in linked pelagic-benthic systems, where components of either sub-environment can affect components of the other.

In most experimental ecosystems that do include both pelagic and benthic elements, the benthos is simply placed at the bottom of the pelagic tank. This introduces a mismatch in benthic and pelagic turbulence scales, discussed above in the context of benthic mass transfer. Benthic organisms also are affected by the artificial flow environment (Nowell \& Jumars 1984, Snelgrove \& Butman 1994). For example, feeding behavior and efficiency (Carey 1983, Muschenheim 1987. Monismith et al. 1990, Grizzle et al. 1992 Taghon \& Greene 1992, Butman et al. 1994) and larval settlement (Butman 1987, Pawlik \& Butman 1993) are affected by the presence or absence of horizontal flow and horizontal particle flux. The relevant velocity scale for these processes is the mean shear velocity, $u_{.}$, and the relevant length scale near the bottom is the bottom roughness, $k_{b}$ (Butman 1986, Muschenheim 1987). Thus, experimental ecosystems containing benthos should add 3 more variables for scale comparisons: the mean and variance of $u$. and a typical value of $k_{b}$. Natural boundary layers presumably are characterized by larger $u$. means and smaller $u$. variances than conventionally mixed experimental ecosystems (except perhaps for wave-dominated environments; Denny 1988).

\section{Summary}

The 2 most important turbulence parameters for experimental ecosystem research are overall mixing time, $T_{m}$ and turbulence dissipation rate, $\varepsilon$, the former representing the effects of large-scale mixing and the latter the effects of small-scale shear. $T_{m}$ is a very useful measure of large-scale mixing effects in experimental ecosystems. In general the boundary mixing time (Eq. 17) is best for boundary flux problems and the central mixing time (Eq. 18) is best for internal dispersion problems. Ratios of $T_{m}$ to characteristic ecosystem times, such as population turnover time (Eq. 19) or particle settling time ( $\mathrm{Eq} .20$ ), reveal much about overall distributions and characteristics of associated ecosystem components. There are 2 important caveats, however. First, $T_{m}$ is loosely defined in the sense that its definition depends on the choice of a reference point within the ecosystem enclosure and the choice of a level of uniformity that is to be considered mixed. Second, caution must be used when comparing estimates of $T_{m}$ based on different definitions, since most definitions of $T_{m}$ assume a constant eddy diffusivity that is valid only in a limited sense. $\varepsilon$ is the controlling physical factor for a wide variety of ecosystem processes, ranging from mass transfer across boundaries to predator-prey interaction to small-scale patchiness. Many of these processes depend on a local value of $\varepsilon$ that may be quite different from the average value, such that it is just as important to measure the distribution of $\varepsilon$ within an enclosure as it is to determine its average value.

Spatial and temporal variability of turbulent mixing also may be expressed in terms of $T_{m}$ and $\varepsilon$. The time history of $T_{m}$ is an important indicator of large-scale temporal variability. The skewness and kurtosis (the 3 rd and 4 th moments) of the probability distribution of $\varepsilon$ are a good measure of the likelihood of rare large events and the degree of intermittency that affect small-scale processes.

When benthic processes and benthic-pelagic coupling are important, 3 more important turbulence scales are added. These are the mean and variance of the bottom shear velocity, $u$, and a typical value of the bottom roughness, $k_{b}$.

Many important processes in experimental ecosystems are affected by turbulence at all scales. Particle cycling is a good example. Large-scale distributions of settling particles are controlled by the mixing time and the settling velocity (Eq. 20). The settling velocity is influenced by aggregation and disaggregation processes, which are controlled by small-scale turbulence. Resuspension and deposition processes may be thought of as mass transfers across the sediment-water interface controlled by parameters similar to those discussed in connection with Eq. (21) and by the time variability of benthic boundary layer flow (Mehta 1988, Sanford \& Chang 1997). Thus, if particle cycling is to be considered from a system perspective, the implica- 
tions of ignoring or distorting turbulence characteristics at any scale must be considered carefully.

\section{IMPLEMENTING AND QUANTIFYING TURBU- LENT MIXING IN EXPERIMENTAL ECOSYSTEMS}

Important features of natural turbulence and important mixing scales for experimental ecosystem research have been identified in the preceding sections. No less important are the practical questions of how to implement a mixing scheme and how to gauge its performance. This section explores various aspects of implementing and quantifying realistic turbulent mixing in experimental ecosystem enclosures. It is organized into subsections on general considerations and constraints, lessons from chemical engineering, existing experimental ecosystem mixing schemes, techniques for measuring turbulent mixing in enclosures, and dimensional analysis.

\section{General considerations and constraints}

There are a number of mixing considerations for experimental ecosystems that are more practical than theoretical. Many of these are little more than common sense, bul they should be enumerated both for completeness and because they impose constraints on the design of a mixing system. The most important are

(1) Size: There are minimum dimensions for mesocosms based on organism size and behavior (Guanguo 1990), light extinction (Menzel \& Case 1977), trophic complexity (Kuiper et al. 1983), and sampling requirements. Size also is an issue with regard to the state of the turbulence (Osborn \& Scotti 1996). Targeted natural turbulence dissipation levels often are quite low (Table 1). If the turbulence generation apparatus is small, the integral length scale $l$ will be small and the turbulence Reynolds number, $\operatorname{Re}_{l}=u_{\text {RMs }} l / \mathrm{v}=\varepsilon^{1 / 3} l^{4 / 3} / \mathrm{v}$, may be too low for true turbulence $(<100$; Oldshue \& Herbst 1990).

(2) Time scales: The mixing time $T_{m}$ has been emphasized here (Eqs. 17-20), but there are a number of other important experimental ecosystem time scales that must be considered in relation to natural ecosystem time scales. These include flushing time relative to generation times for species of interest (an important determinant of ecosystem variability; Lewis \& Platt 1982), on-off cycling of mixing relative to endogenous rhythms in nature (e.g. the tidal cycle), and on-off cycling of light relative to the natural diel cycle.
(3) Non-interference: The mixing apparatus should not block light significantly (when this is an issue), nor should it disturb organisms significantly (Øiestad 1990)

(4) Cost: Costs of constructing and maintaining a mixing system should not be so large as to limit replication or repetition of an experiment.

(5) Durability: Ecosystem experiments often run for extended periods of time, and environmental conditions frequently are not very hospitable for complex mechanical systems. A good mixing system design will stand up to sustained use over long periods without frequent interruption for maintenance or repairs.

(6) Benignity: Mixing components should not contaminate or otherwise affect the environmental quality of an ecosystem enclosure, and they should not retain nutrients or contaminants from one experiment to the next. Heat generated by the mixing apparatus should not significantly change the temperature of the enclosure.

(7) Wall shear: The walls of ecosystem enclosures are the source of some of the most significant artifacts in experimental ecosystem research (Oviatt 1994). High shear at the walls results in little if any mass transfer limitation for wall communities. Mixing schemes that cause large shear at the walls relative to the surface, bottom, and interior of an enclosure should be avoided. This is especially important if the growth of wall communities cannot be controlled by frequent wall cleaning.

(8) Scope: If an experiment is limited in scope, the scale and complexity of the mixing apparatus can be limited accordingly. For example, experiments on benthic recruitment can concentrate on representing the benthic environment accurately, as long as primary production, nutrient cycling, and trophic interactions in the plankton are not a concern (Butman 1987, Findlay et al. 1992, Grassle et al. 1992). Experiments on attached or tethered organism behavior under turbulent conditions can concentrate on flow and turbulence in the vicinity of the organism alone (Costello et al. 1990, Johnson \& Sebens 1993. Hwang et al. 1994) The definition of experimental ecosystem is stretched by inclusion of these limited situations, but that is not the issue here. The point is that simpler can be easier or more accurate, as long as the limitations of simplification are recognized.

\section{Lessons from chemical engineering}

Chemical engineers deal routinely with many of the mixing issues raised here. Mixing is an integral 


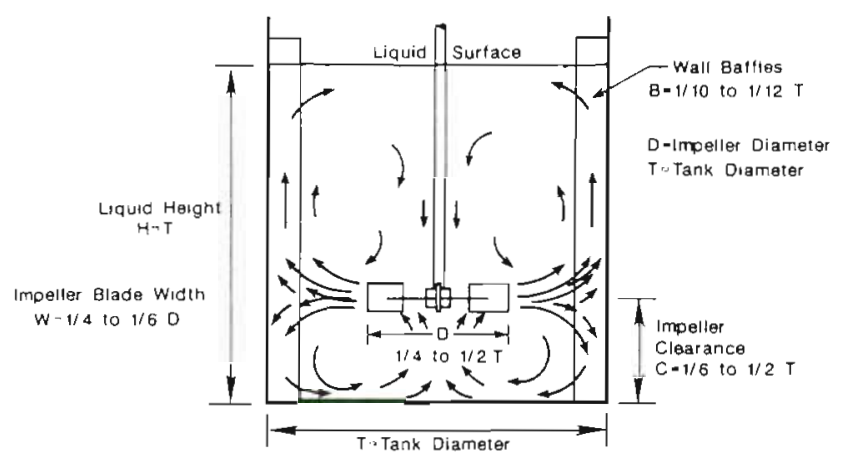

(a)

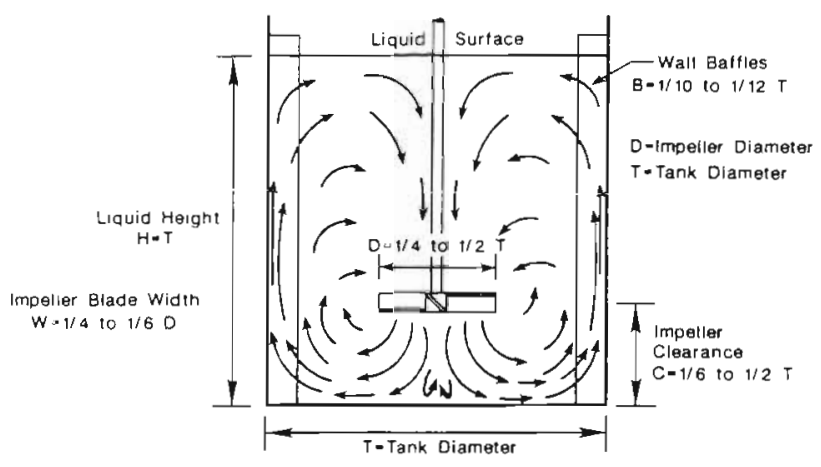

(b)

Fig. 3. Standard tank geometry for chemical engineering mixing tanks, from Tatterson (1991) with the permission of the McGraw-Hill Companies. (a) Radial impeller and associated flow pattern. (b) Axial impeller and associated flow pattern (see also $\varepsilon$ distribution in Fig. 2b)

process in the chemical, petrochemical, biochemical, and waste management industries (Oldshue \& Herbst 1990, Tatterson 1991). The goals of chemical process mixing differ significantly from the goals of experimental ecosystem mixing, however. In most cases, chemical engineers want to maximize the rate of a mixing-controlled reaction, such that mixing rates, turbulent energies, and Reynolds numbers are all much higher than is acceptable for experimental ecosystem research. Perhaps the closest chemical engineering analog to an experimental ecosystem is an industrial fermentor, where a community of microbes is the prime concern (Feijen \& Hoffmeester 1992). In any case, the design principles used by chemical engineers for mixing tanks are a useful touchstone for ecologists. Similar conceptual transfers from chemical engineering have been invoked in other areas of ecology (Penry 1989, Patterson 1992).

Much of the chemical engineering literature on mixing deals with impeller designs, flow patterns, and turbulence characteristics in a 'standard tank geometry' (Oldshue \& Herbst 1990. Tatterson 1991; the remainder of this subsection is drawn from these 2 references unless otherwise noted) Typical dimensions and flow patterns of standard geometry tanks are indicated in Fig. 3. A standard tank is cylindrical and as wide as it is decp, with a single impeller at approximately $2 / 3$ depth that is rotated unidirectionally about a vertical axis. The spin imparted to the flow by the impeller is broken up and converted to vertical stirring by vertical baffles on the walls. Two types of impeller are used: a horizontal disk with vertical blades known as a radial impeller that drives an outward flow, and an open set of pitched blades known as an axjal impeller that drives a vertical flow.

Three powerful concepts from chemical engineering mixing studies may be transferred to experimental ecosystem studies, not including mechanical design considerations. The first is that the power put into mixing, which is equal to the power dissipated by turbulence at steady state, may be written as a function of the yeometry of the system and the rate of impcller rotation:

$$
\varepsilon=\frac{P}{\rho V}=\frac{N_{p} N^{3} D^{5}}{V}
$$

where $\varepsilon$ is the volume averaged dissipation rate, $P$ is applied power (in $W=\mathrm{kg} \mathrm{m}^{2} \mathrm{~s}^{-3}$ ), $V$ is tank volume (in $\left.\mathrm{m}^{3}\right), N_{p}$ is the dimensionless, empirically determined power number, $N$ is impeller rotation rate (in $\mathrm{s}^{-1}$ ), and $D$ is impeller diameter (in $\mathrm{m}$ ). Note that the average value of $\varepsilon$ on the left-hand side of Eq. (24) does not indicate the variability of $\varepsilon$ within the tank. It typically varies over almost 2 orders of magnitude, with the highest values in a small region around the impeller (Fig. 2b). Several ecological researchers also have estimated average $\varepsilon$ by measuring the power put into mixing at steady state (Nixon et al. 1980, Kiørboe et al. 1990, Peters \& Gross 1994), with mixed success (discussed below).

The second important concept is the use of scale models for mixing system design and evaluation. The power number $N_{p}$ may be shown to be a function of the geometry of the tank-mixer system and an impeller Reynolds number, $\operatorname{Re}_{D}=N D^{2} / \mathrm{v}$ :

$$
N_{F} \propto \operatorname{Re}_{D}^{\theta} \times \text { nondimensional geometric terms }
$$

The exponent $\alpha$ varies with Reynolds number between $\alpha=-1$ for low Reynolds numbers and $\alpha=0$ for high Reynolds numbers. For high Reynolds numbers and similar geometries (e.g. the standard tank geometry), $N_{P}$ is approximately constant. Eq. (25) allows scale modeling of tank mixing in which the size of the system is scaled down and the rotation rate is scaled up to maintain the same Reynolds number. Flow and turbulence characteristics are then identical between a small-scale model and a full-scale prototype. An obvious advantage of this approach is that laboratory-scale 
Fig. 4. Schematic of 2 mixing schemes in the MERL mesocosms at the Unuversity of Rhode Island, USA, from Donaghay \& Klos (1985). The vertical plunger on the left was the onginal mixing design. It has gradually been replaced by the rotating paddlef bar design on the right, which was developed to enable a stratified water column experiment to be performed. Stratification can be eliminated by placing mixing bars throughout the water column. The direction of paddle rotation is reversed periodically to avoid spin-up of the water column. In both designs, mixing is turned off for 2 to $4 \mathrm{~h}$ every $6 \mathrm{~h}$ to simulate tidal slack

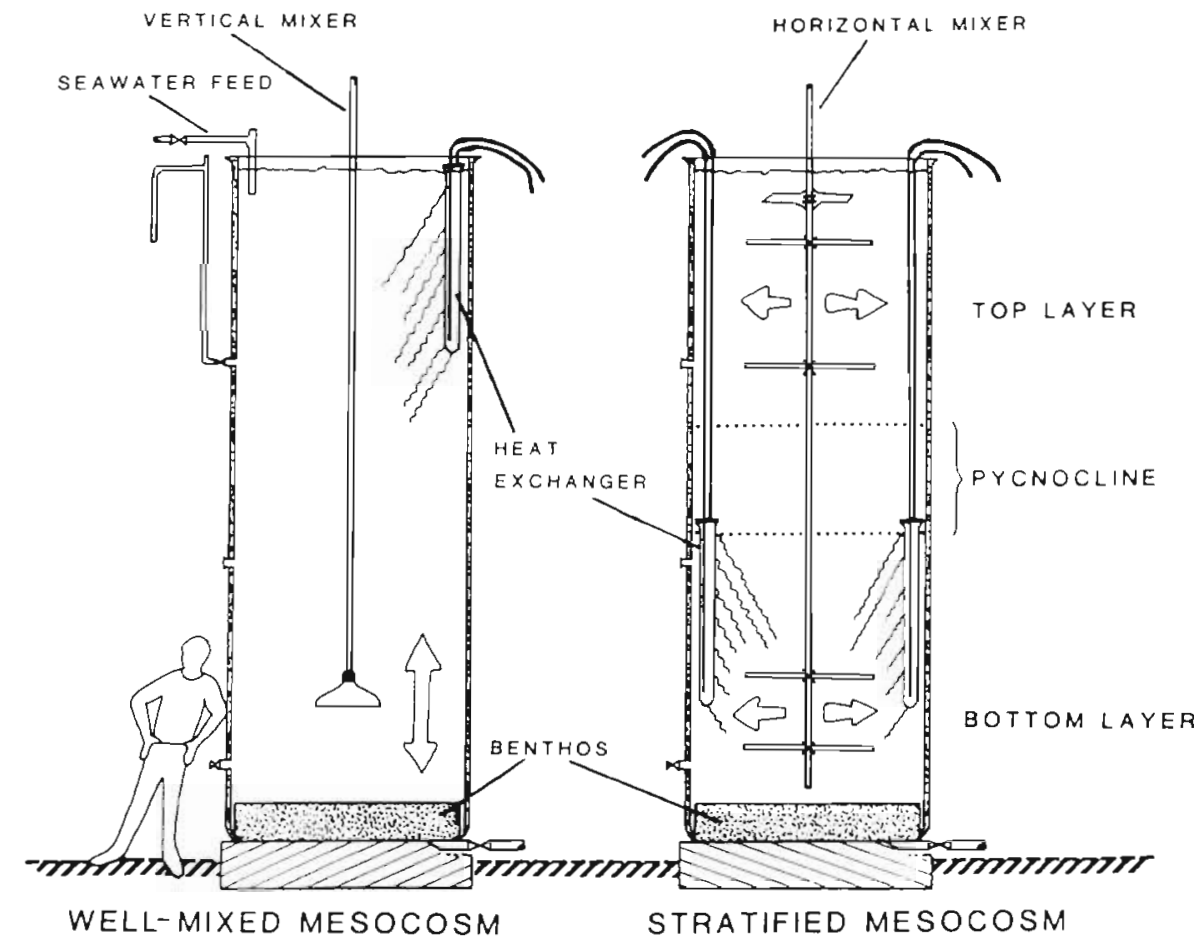

Existing experimental ecosystem mixing schemes modify than full-scale prototypes. The possibilities of scale modeling in experimental ecosystem research are discussed below in connection with the use of dimensional analysis techniques in ecology.

The third important concept is that mixing in tanks can be separated into what chemical engineers refer to as flow and shear. In more familiar terms, flow is equivalent to circulation or stirring and shear is equivalent to turbulent dissipation in the vicinity of the impeller. The design of the impeller controls the ratio between flow and shear. Large, slowly spinning axial impellers promote flow, while small, rapidly spinning radial or unpitched axial impellers promote shear. High-flow/ low-shear mixing is most effective for stirring and suspension of particles, while low-flow/high-shear mixing is most effective for promoting small-scale particle contact and dispersion. Clearly, neither extreme is desirable for experimental ecosystem studies. Highflow mixing tends to transfer most of the turbulence production and energy dissipation to the walls. Highshear mixing tends to create local zones of intense dissipation with little exchange between different parts of the tank. A balance between the two is desirable. The right amount of flow will help with large scale dispersion and will ensure that all of the water in an ecosystem enclosure is carried past the impeller at some point, while the right amount of shear will mimic the range of dissipation rates likely to be encountered by an organism in its natural environment.
Mixing, like many other aspects of experimental ecosystem design, is something that everyone does differently. There are, however, several general categories into which existing schemes can be placed. These include rotating paddles and oscillating grids in tanks, flexible-walled in situ enclosures, stirred benthic chambers and flumes, and miscellaneous other schemes including bubbling, pumping, and shaking of a variety of enclosures. A few selected examples are presented here to illustrate the range of designs and to discuss advantages and disadvantages of different schemes.

Rotating paddle mixers are similar to the standard chemical engineering mixing scheme shown in Fig. 3. They are used in land-based, rigid-wall enclosures. In this design, paddles or mixing bars are rotated about a vertical axis to produce turbulence along with varying levels of circulation. Rotation is periodically stopped and reversed to avoid spinning up the water column in one direction. Examples include the MERL mesocosms at the University of Rhode Island, USA (Donaghay \& Klos 1985, Klos 1988), the RIKZ mesocosms in Jacobahaven, The Netherlands (Peeters et al. 1993, Prins et al. 1994), and the MEERC mesocosms at the University of Maryland, USA (L. Sanford, S. Suttles, E. Porter \& R. Calabrese unpubl.). The MERL systems are illustrated in Fig. 4. The original mixing scheme in MERL was a vertically oscillating plunger, which maintained a well 


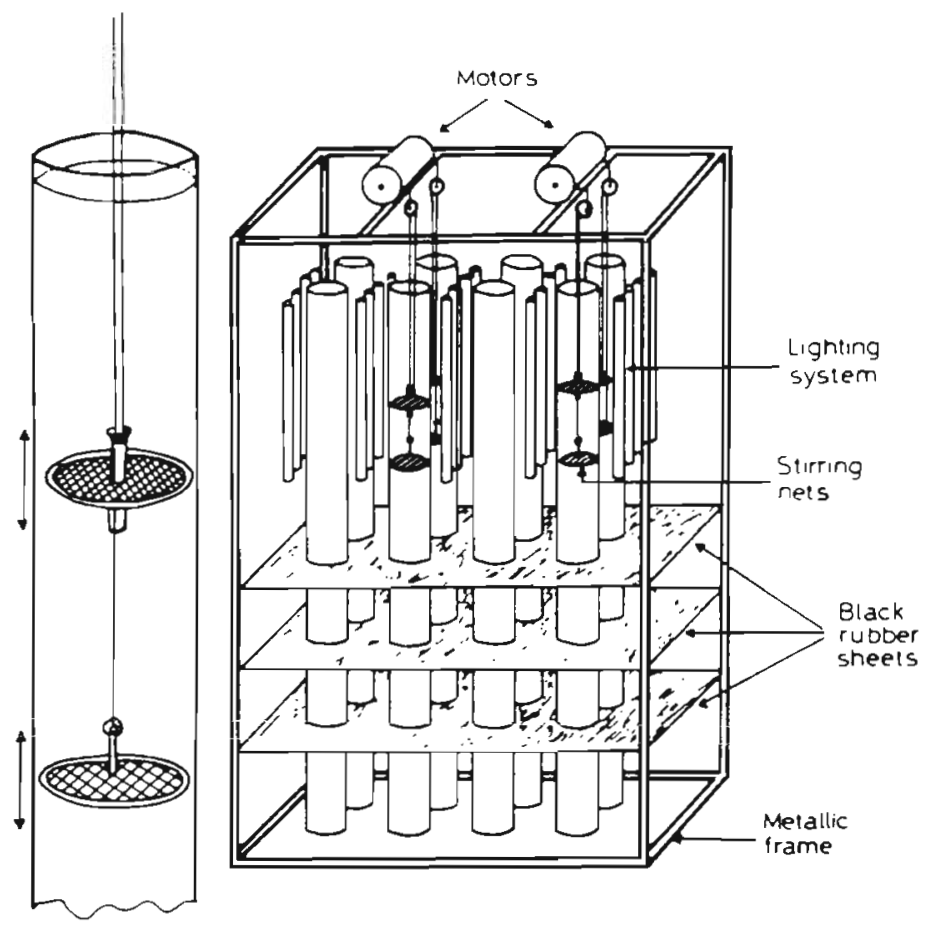

Fig. 5. Oscillating grid mixing scheme used by Estrada et al. (1987). Two circular pieces of netlon netting of $6 \mathrm{~mm}$ mesh size oscillated up and down in the upper part of $15 \mathrm{~cm}$ diameter culture vessels to stir the lighted surface layer. Other investigators (e.g. Howarth et al. 1993) have used oscillating grid systems in larger tanks with larger grid elements

mixed water column with artificially high vertical exchange (Nixon et al. 1980). Rotating paddles were introduced to enable a stratified water column experiment to be conducted (Donaghay \& Klos 1985), but they have become standard for most recent MERL experiments (E. Klos, University of Rhode Island, pers comm.).

Rotating paddle mixers can simulate the major features of natural water column turbulence. Experimental ecosystems mixed with rotating paddles are capable of sustaining a realistic acquatic ecosystem for extended periods of time. Rotating paddles may be used to maintain either a well-mixed water column or 2 well-mixed layers separated by a pycnocline. Sanford et al. (unpubl.) have shown that chemical engineering scaling rules (e.g. Eq. 24) are in qualitative agreement with the behavior of the rotating paddle mixing systems in the MEERC mesocosms. Because the systems are accessible, maintenance and wallcleaning are relatively straightforward. Disadvantages of this mixing design include a practical upper limit on volume (the MERL tanks are the largest at $13 \mathrm{~m}^{3}$ ), expenses of construction, and an artificially low energy benthic environment unless the internal mixing energy is increased in compensation (Prins et al. 1994). Disturbance of organisms by the paddles and initiation of experiments with realistic natural populations do not seem to be major problems in practice (B. Sullivan, MERL, pers. comm.).

Oscillating grids have been used by a number of investigators to generate turbulence at a variety of scales and in 2 different modes. A schematic of an oscillating grid mesocosm mixing system is shown in Fig. 5. Oscillating grids are used most often in rigid-walled land-based tanks ranging in size from laboratory beakers (Kiorboe et al. 1990, Peters \& Gross 1994) through microcosms containing tens of liters of water (Estrada et al. 1988, Hwang et al. 1994 Landry et al. 1995) to mesocosms of several $\mathrm{m}^{3}$ volume (Howarth et al. 1993).

The first mode of grid operation is a short, relatively rapid oscillation centered on a fixed location (Estrada et al. 1987, Kiørboe et al. 1990 Saiz et al. 1992, Howarth et al. 1993. Hwang et al. 1994, Landry et al. 1995, Brunk et al. 1996). This mode has several advantages. A large portion of the water column is undisturbed, there are good published measurements of oscillating grid turbulence (Brumley \& Jirka 1987, Hill et al. 1992, Howarth et al. 1993, Brunk et al. 1996), and direct measurement of mixing power is possible through the use of force and displacement transducers (Kiørboe et al. 1990). The major disadvantage of this mode of operation is that there is an extremely large gradient in turbulent dissipation rate away from the center of oscillation. Turbulent dissipation rate decays approximately as distance $^{-4}$ in the vicinity of the grid (Brumley \& Jirka 1987). In addition, there is little net circulation to stir the water column, such that the various subregions of the tank may be poorly connected. The second mode of grid operation is a longer, slower oscillation, with the grid passing through most of the water in the tank at least once per cycle (Peters \& Gross 1994). This mode ensures more homogeneous turbulence, but it may be more disruptive to delicate organisms and it is more difficult to sample. Other potential disadvantages of both modes of operation include grid interference with the light field and an artificially low energy benthic environment.

Flexible-wall in situ experimental ecosystems have been used by aquatic ecologists for nearly 40 years (Banse 1982, SCOR Working Group 85 1990). These enclosures tend to be deep, relatively narrow bags constructed of thin, clear plastic sheeting (Menzel \& Case 1977, Grice \& Reeve 1982). They usually are supported at the surface by floatation rings, with the walls 
kept vertical by weighted shrouds, guy wires, or an adjacent structure. Fig. 6 is an illustration of the flexible-wall in situ enclosures used in the CEPEX field program carried out in Saanich Inlet, British Columbia, in the late 1970s (Menzel \& Case 1977, Grice \& Reeve 1982). Advantages of these systems are that a large volume of in situ water and most of its associated organisms can be captured with little disturbance, that incident light is more natural than in many other experimental ecosystems, and that temperatures are naturally controlled by the surrounding water Disadvantages include a somewhat greater difficulty of sampling and the fact that these systems seldom include benthos (but see Riemann et al. 1988, Chrost \& Riemann 1994).

The most important drawback of flexible-wall enclosures, however, is that mixing is greatly reduced. For example, Steele et al. (1977) estimated vertical turbulent diffusivities of approximately $0.1 \mathrm{~cm}^{2} \mathrm{~s}^{-1}$ in the CEPEX enclosures. This is larger than molecular diffusivity; Steele et al. (1977) speculated that a certain amount of mixing was induced by instantaneous temperature exchange across the walls, nighttime convection, and wave forcing at the surface. However, $0.1 \mathrm{~cm}^{2}$ $\mathrm{s}^{-1}$ is at least an order of magnitude smaller than turbulent diffusivity in the natural surface layer. As a result, the CEPEX enclosures were artificially stratified with virtually no upward nutrient flux (Takahashi \& Whitney 1977), and larger phytoplankton settled out rapidly after initiation of the experiments (Eppley et al. 1978). Absence of large scale mixing almost certainly meant little turbulent energy at small scales, which likely affected trophic interactions within the enclosures as well. Brief daily mixing by bubbling was sufficient to reestablish a more normal plankton (Eppley et al. 1978, Sonntag \& Parsons 1979), but the temporal pattern and intensity of mixing were not natural.

Small flexible-wall enclosures narrower than the wavelength of prevailing waves do seem to be better mixed (Gust 1977. Takahashi \& Whitney 1977). Chrost \& Riemann (1994) also report on experiments in flexiblewall systems stirred by 'wind-driven mills', but no further details are given. Watanabe et al. (1995) describe a jetpipe scheme for stirring the upper few meters of moored enclosures, which was sufficient to prevent sedimentation of the larger phytoplankton. They provide a reasonable description of the resulting circulation, but no turbulence measurements appear to have been made. In addition, their scheme requires an external power source to run the pumps. The general lack of schemes for implementing controlled mixing in flexible-wall experimental ecosystem enclosures should be addressed, as should the lack of data on turbulence characteristics in these systems. This is especially true in light of some of the other advantages of these systems.

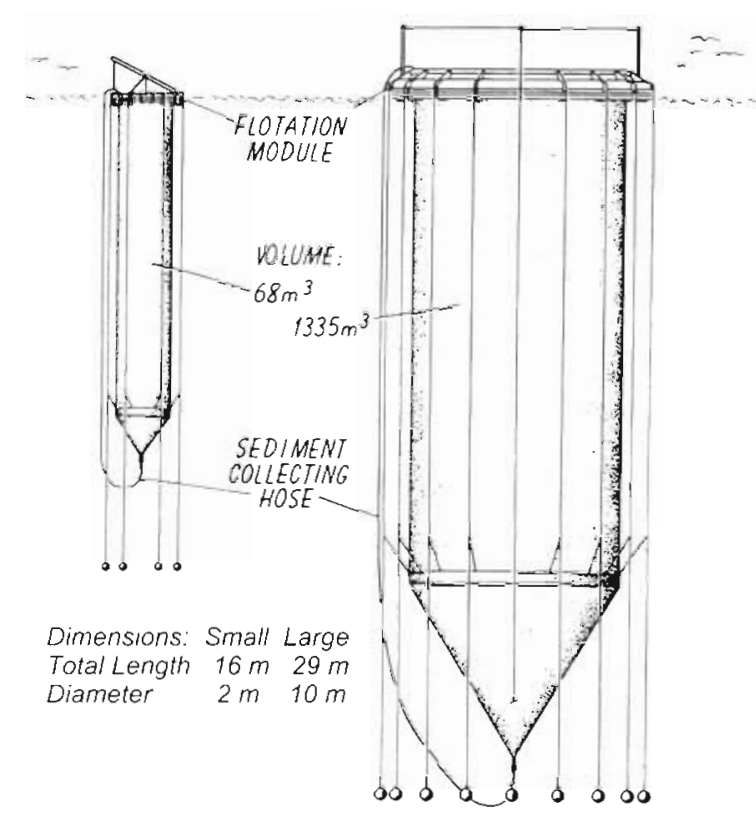

Fig. 6. Schematic of 2 flexible-wall in situ enclosures used in the CEPEX study in Saanich Inlet, BC, Canada, in the late 1970s, from Grice \& Reeve (1982) by permission of Springer-Verlag, Inc. In most experiments, the enclosures were not mixed other than by naturally induced motion of the walls and nighttime cooling, though Eppley et al. (1978) and Sonntag \& Parsons (1979) describe experiments with bubbling. The small-diameter enclosures were better mixed than the large-diameler enclosures, but both designs were significantly under-mixed relative to the external water column

Air bubbling is a mixing scheme with precedents in chemical engineering but very few published applications in experimental ecosystems. In chemical process mixing, bubbling is most often used in metallurgical applications. A useful relationship for the average dissipation rate produced by bubbling is

$$
\varepsilon \approx \frac{P}{\rho V}=\frac{Q g H}{V}
$$

where $Q$ is the volume flow rate of the gas (in $\mathrm{m}^{3} \mathrm{~s}^{-1}$ ), $g$ is gravitational acceleration (in $\mathrm{m} \mathrm{s}^{-2}$ ), and $H$ is the depth of bubbling (in $\mathrm{m}$ ) (Tatterson 1991). Details of mixing produced by bubbling depend on the location of bubble injection. In experimental ecosystem applications, Eppley et al. (1978) and Sonntag \& Parsons (1979) bubbled the CEPEX enclosures to keep larger phytoplankton suspended and to resupply nutrients to the upper part of the water column, respectively. An appropriate duration and frequency of bubbling were guessed at in both cases, and adjusted as necessary to achieve the desired results

Recirculation by pumping has been used on occasion for mixing purposes (e.g. Kotak \& Robinson 1991). While attractive in its simplicity, pumping is not a very 


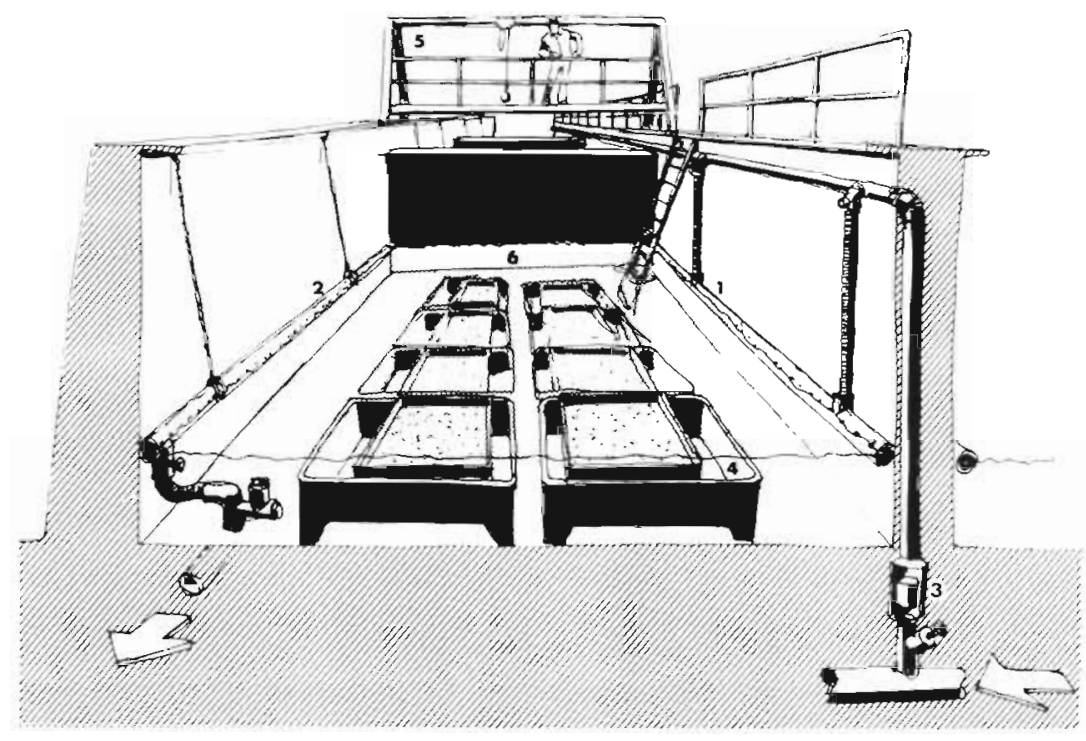

Fig. 7. Schematic of a soft-bottom sublittoral benthic mesocosm on the Oslofjord, Norway, from Berge et al. (1986) by permission of Ophelia Publications. (1) Perforated tube for inflow of water; (2) perforated tube for outflow of water; (3) flowmeter; (4) sediment boxes; (5) moveable bridge; $(6)$ dividing partition. By controlling flow rate, water depth, and light, the system can reproduce the basic features of the benthic environment. Realistic distributions of bottom shear stress (Nowell \& Jumars 1987) require more sophisticated technologies

realistic representation of natural turbulence. Pumping tends to produce flow with low shear in the interior of the experimental ecosystem enclosure and very high shear in the pump/hose assembly. If the fluid is reintroduced into the tank as a jet, it can contribute to mixing in the enclosure; in this case there are precedents in the chemical engineering literature (Tatterson 1991) and interior mixing may be more realistic

Benthic experimental ecosystem studies may be classified as in situ plots, channels, tunnels, or enclosures with varying degrees of connection to the surrounding environment (e.g. Asmus et al. 1992, and see Banse 1982), and land-based facilities with sediments and organisms transplanted from the field (e.g. Silverberg et al. 1995). A separate classification into soft-bottom (de Wilde 1990) or hard-bottom (Bakke 1990) ecosystems may be made as well. In situ benthic studies are not affected as seriously by advective changes as are plankton studies, since many of the organisms of interest are fixed to the bottom. This fact, along with the difficulties of transporting undisturbed sediment and benthos from the field and the long periods of adjustment required before experiments can begin (de Wilde 1990), have tended to restrict interest in landbased benthic ecosystem studies. However, de Wilde (1990) points out that in situ studies seldom have true experimental control over the environment. When this control is important, land-based benthic ecosystem enclosure studies are a viable alternative.

A reasonable representation of the benthos can be maintained in a benthic ecosystem enclosure by simple flow-through (Berge et al. 1986, Bakke 1990) or internal recirculation (Silverberg et al. 1995). Fig. 7 shows one such enclosure at Solbergstrand on the east side of the Oslofjord, Norway. A number of flow artifacts may be present, however, most of which have been discussed above. For example, too little flow can have a profound effect on decomposition and regeneration processes (Tenore 1987), largely through mass transfer limitation. Similar systems constructed to mimic hardbottom intertidal benthos have added regular surface wave forcing to the flow-through (Bakke 1990). A caveat to all of these systems is that unrealistically regular flow patterns can artificially structure the benthos within an enclosure (Bakke 1990). Attempts to match in situ boundary layer flow by the use of open channels aligned into the flow (Asmus et al. 1992) can be successful with careful design, but flow disturbance by the physical structure may result in entrance condition and container artifacts (Snelgrove et al. 1995). Stirring away from the boundary can produce realistic sediment-water fluxes (Cahoon 1988, Buchholtz-ten Brink et al. 1989, Glud et al. 1995), but at a cost of too much internal energy. Small scale pressure gradients induced by stirring an enclosure also may result in advective flushing of pore waters in sandy sediments (Huettel \& Gust 1992).

Many of these problems may be addressed through careful flume design and construction (Muschenheim et al. 1986. Nowell \& Jumars 1987, Butman et al. 1994, Grizzle et al. 1994, G. Taghon, Rutgers University, USA, pers. comm.), but frequently such facilities are quite expensive and complex. An even larger question has to do with realistic coupling of pelagic and benthic environments in one system. There do not appear to be any published experimental ecosystem designs that adequately reproduce both mixing of the water column and the flow environment of the benthos, although at least one example of such a design is being tested (Porter et al. 1997). At this time benthic-pelagic link- 
age remains an important but unsolved problem in experimental ecosystem design.

\section{Techniques for measuring turbulent mixing in enclosures}

Quantifying turbulence can be an intimidating prospect for an ecologist untrained in physical oceanography or fluid mechanics. There are, however, a number of straightforward techniques for quantifying the important mixing characteristics identified here. Several of these techniques do not require specialized equipment or analysis. In addition, recent instrumentation developments have made direct measurement of turbulence in experimental ecosystem enclosures less expensive and less complicated than in the past

The best method for estimating $T_{m}$ is through dye dispersion techniques, according to its definition (Eq. 17 or 18). Measurements of $T_{m}$ by dye dispersion have been reported for several rotating paddle or plunger mixers (Nixon et al. 1980, Bonner et al. 1992, Peeters et al. 1993, Sanford et al. unpubl.) and for flexible-wall in situ enclosures (Steele et al. 1977). The dye dispersion technique also is used in chemical engineering mixing studies (Tatterson 1991) and in physical oceanography (e.g. Ledwell et al. 1993). A small amount of tracer-labeled neutrally buoyant fluid is injected either at the surface or at mid-depth and samples are taken at several locations in the enclosure over time. The mixing time is defined by tracer concentration reaching a specified degree of uniformity throughout the enclosure. The eddy diffusivity, $K_{D}$, may be estimated by solving Eq. (17) or (18), or by fitting a diffusion model to the time/depth series (Steele et al. 1977. Bonner et al. 1992). Comparisons between $T_{m}$ evaluated using different injection points may help to decipher spatial variation of $K_{D}$. A very useful exercise (Tatterson 1991, Peeters et al. 1993, Sanford et al. unpubl.) is measurement of $T_{m}$ versus mixer speed (e.g. paddle rotation rate).

In the absence of direct measurements of velocity, gypsum dissolution techniques may be used to estimate interior velocity scales (Petticrew \& Kalff 1991, Howerton \& Boyd 1992, Thompson \& Glenn 1994, Sanford et al. unpubl.) and bottom shear velocity scales (Opdyke et al. 1987, Buchholtz-ten Brink et al. 1989, Santschi et al. 1991). In this technique, carefully prepared, dried and preweighed gypsum blocks, spheres, or plates are deployed for a few hours in the flow of interest, then dried and reweighed. The rate of weight loss generally has been found to be proportional to some velocity scale raised to a power $\leq 1$. Care must be taken to correct dissolution rates for differences in temperature, salinity, composition, and water chemistry. The dissolution rate versus speed calibration depends on the size, shape, and Reynolds number regime of the blocks or plates as well. This means that, in practice, gypsum dissolution techniques must be calibrated for each application to obtain quantitative results. However, gypsum dissolution is useful as a relative measure even without calibration data (Oviatt et al. 1977, Nixon et al. 1980). A caveat is that equal gypsum dissolution rates in 2 different environments only indicate equal scale velocities in a limited sense. If the nature of the flow is different but the scale velocity is similar (e.g if $U$ in steady flow is approximately the same as $u_{R M S}$ in fluctuating flow), gypsum dissolution measurements will indicate a misleading similarity. It also is important to note that equal gypsum dissolution rates do not indicate equal $\varepsilon$; $\varepsilon$ can be significantly different if $l$ is significantly different (Eq. 13), in spite of similar values of $u_{R M S}$.

Several flow sensors are available for direct measurement of turbulent velocities in experimental ecosystems. These include laser doppler velocimeters (LDVs; Hill et al. 1992), hot wire (Gust 1977) and hot film (Howarth et al. 1993) probes, small acoustic velocity sensors (Kraus et al. 1994, Trivett \& Snow 1995), and small electromagnetic velocity sensors (Howarth et al. 1993). Flush-mounted hot-film probes also are available for measurement of $u$. (Gust 1988). Important requirements for such a sensor are a size much smaller than $I$, response time and sampling rate much faster than $/ / U$, and directionality of response. Sensors that do not satisfy these requirements, such as a large diameter electromagnetic current meter or a nondirectional hot bead thermistor, are not appropriate for turbulence measurements at small scales. The data logging system also must be capable of accurate, rapid recording of long velocity time series. In the past, these requirements have been beyond the capability of many experimental ecosystem facilities and beyond the expertise of many ecologists. However, recent improvements in technology (e.g. Kraus et al. 1994) are making direct turbulence measurements much simpler and more affordable.

Measurement of turbulent velocities in ecosystem enclosures is much the same as in nature. Velocity sensors either are held in a fixed location, measuring time series of velocity fluctuations at a point (Gust 1977. Howarth et al. 1993, Sanford et al. unpubl.), or they are traversed rapidly through the turbulent velocity field, effectively measuring a space series of velocity fluctuations (Hill et al. 1992, Howarth et al. 1993).

One method for calculating $\varepsilon$ from turbulent velocity measurements is based on the level of the turbulence energy spectrum in the inertial subrange (Eq. 8). The spectrum is expressed in terms of spatial rather than 
temporal variation, which is well suited for spatially traversed velocity measurements. A velocity scale for converting time series to space series is needed for fixed point velocity measurements. The mean velocity is used for this purpose in natural flows, but often there is very little mean velocity in enclosures. Tennekes \& Lumley (1972) offer a solution to this dilemma by suggesting that $u_{R M S}$ is the appropriate velocity scale for zero-mean flow, but they leave a critical multiplicative constant undefined for lack of data. Terray et al. (1996) indicate that the value of that constant under nearsurface breaking waves should be approximately the same as it is for mean flow, leading to the formula

$$
\varepsilon=\frac{1}{u_{R M S}} 1.9\left[E(\omega) \omega^{\frac{5}{3}}\right]^{\frac{3}{2}}=\frac{2 \pi}{u_{R M S}} 1.9\left[E(f) f^{\frac{5}{3}}\right]^{\frac{3}{2}}
$$

where $E$ represents the 1 -dimensional variance spectrum of the transverse component of velocity (Eq. 8), $\omega$ is radian frequency $\left(\mathrm{s}^{-1}\right)$ and $f$ is cyclic frequency $(\mathrm{Hz}$ or cycles $\mathrm{s}^{-1}$ ). Eq. (27) is a reasonable choice for estimating $\varepsilon$ in ecosystem enclosures.

Another technique for estimating $\varepsilon$ from measured velocity fluctuations involves calculating $u_{R M S}$ from measured data, estimating $I$, then estimating $\varepsilon$ from Eq. (13). An advantage of this technique is that $u_{R M S}$ may be determined from calibrated gypsum dissolution measurements as well as from direct velocity measurements (Sanford et al. unpubl.). I may be estimated from a space series of velocity according to Eq. (5), from some assumed relationship to the turbulence generation mechanism (Howarth et al. 1993), or from data collected previously under similar conditions (Brumley \& Jirka 1987). For example, Hill et al. (1992) obtained very good estimates of dissipation in grid-generated turbulence by using Eq. (13), assuming $A_{1}=1$ with $u_{R M S}$ and $I$ calculated from a velocity component measured parallel to the direction of traverse of a LDV. Howarth et al. (1993) also employed this technique to obtain reasonable estimates of $\varepsilon$ by assuming $l$ was the same as the spacing of the bars in their turbulencegenerating grid. Because many ecosystem processes depend on $\varepsilon$ raised to some fractional power, small uncertainties in the values of $I$ and $A_{1}$ are less important than might otherwise be the case. For example, rearranging Eq. (13) gives

$$
\varepsilon^{\frac{1}{3}}=\left(\frac{A_{1}}{l}\right)^{\frac{1}{3}} u_{R M S}
$$

such that errors of \pm a factor of 2 in $A_{1} / l$ only lead to errors of \pm a factor of 1.26 in $\varepsilon^{1 / 3}$.

Other methods for estimating $\varepsilon$ have been utilized as well. Peters \& Gross (1994) estimated $\varepsilon$ in their microcosm experiments by measuring the rate of decrease of turbulent energy following each passage of their tur- bulence-generating grid, which yielded the dissipation rate directly. Chemical engineers frequently determine volume-averaged $\varepsilon$ by measuring the power used in mixing a scale model over the same range of Reynolds numbers as the full-scale mixing tank (Oldshue \& Herbst 1990, Tatterson 1991). This technique has been used for grid stirring of a microcosm by Kiørboe et al. (1990). It is difficult to use in many cases, however, because the power expended in overcoming mechanical friction often dominates the power expended in fluid mixing (e.g. Nixon et al. 1980).

Another technique for estimating the small-scale distribution of flow and turbulence that is possible in the laboratory but generally not possible in nature is tracking of small particle motion through video (Marrase et al. 1990) or time exposure streak photography (Johnson \& Sebens 1993). The assumption that the particles follow the flow accurately allows frame-by-frame estimation of the vclocity field. A sophisticated, computeraided version of this technique, Particle Image Velocimetry (PIV), recently has been developed for fluid dynamics studies (Gray \& Bruce 1995).

Estimates of the mass transfer coefficient, $\beta$, at the surface may be made through careful gas exchange experiments (Nixon et al. 1979, Jaehne et al. 1987). $\beta$ at the sediment-water interface may be determined with flush-mounted hot-film probes or gypsum dissolution measurements (Buchholtz-ten Brink et al. 1989). These techniques also may be used for measuring $\beta$ at the walls of an enclosure. In most experimental ecosystem enclosures, flow at the bottom is too irregular to use standard boundary layer techniques for determining bottom shear stress (e.g. profiles of average flow velocity fit to a theoretical log profile; Grant \& Madsen 1986 , Wright et al. 1992), but such techniques may be used in benthic flumes (Grant et al. 1982, Butman et al. 1994).

\section{Dimensional analysis}

Dimensional analysis is a method for combining all of the variables describing a problem into fundamental dimensionless terms that capture the essence of the problem. It is a tool commonly used by physical scientists and engineers (Fischer et al. 1979, Tatterson 1991) that has been adopted by ecologists (Platt 1981. Legendre \& Legendre 1983, Home \& Schneider 1994). There are 2 primary uses of dimensional analysis. The first is to aid in the analysis of complex systems and data sets. Dimensional analysis can be used in this context to simplify a complex set of governing equations, to formulate testable hypotheses, to design experiments optimally, to identify scale-dependent ecosystem processes, and to present the results of multidimensional experiments in as concise a fashion as 
possible. This is the mode of use most common in ecology (Lewis et al. 1984a, Miller et al. 1984, Patterson 1992, O'Riordan et al. 1993, Horne \& Schneider 1994). The second important use of dimensional analysis is to model systems at different scales through preservation of the value of the most important dimensionless quantities, known as maintaining dimensional similarity. Engineers use this technique routinely for scale modeling of physical systems (Shapiro 1961, Oldshue \& Herbst 1990, Tatterson 1991). The central idea is that distortion of one variable (such as size) in a dimensionless ratio can be compensated by equal and opposite distortion of another (such as flow speed).

It would seem that experimental ecosystem studies might benefit from the second of these uses of dimensional analysis as much as the first. For example, accurate simulation of a $15 \mathrm{~m}$ deep water column in a $3 \mathrm{~m}$ deep ecosystem enclosure would be quite attractive. There are 2 significant limitations to this concept, however. The first is that realistic ecosystem experiments may be too complex for description by a manageable number ( $\leq 3$ ) of important dimensionless ratios. However, for relatively simple ecosystem cases scale modeling may be feasible. The second limitation is that dimensionless ratios between ecosystem parameters and physical parameters almost always contain terms that cannot be distorted because they are set by the biology or geochemistry of the system (e.g. the growth rate $r$ in $\mathrm{Eq}$. 19). Because of this, maintaining dimensional similarity to nature requires replicating the natural large-scale mixing time $T_{m}$ and the natural smallscale dissipation rate $\varepsilon$ in the experimental system. Achieving this while distorting physical scale and appropriately controlling characteristics such as as the optical extinction depth is a daunting task. Under certain circumstances, however, it may be possible.

As an example, consider the case of an experimental ecosystem enclosure of depth $h_{1}$ that is to mimic a wellmixed natural water column of depth $h_{2} \geq h_{1}$. The integral length scale of turbulence in the natural system may be assumed equal to the depth, or $l_{2}=h_{2}$ (this assumption would need to be validated). The integral length scale of turbulence in the enclosure can be controlled to be some fraction of the depth (at least in concept) through careful design of the mixing system, such that $l_{1}=f h_{1}$ where $f \leq 1$. An equation relating the ratio of the mixing times to the ratio of the dissipation rates can be derived by combining these expressions for $l_{1}$ and $I_{2}$ with Eqs. (12), (13), and (17):

$$
\frac{T_{m 2}}{T_{m 1}}=\left(\frac{h_{2}}{h_{1}}\right)^{2}\left(\frac{l_{1}}{l_{2}}\right)^{\frac{4}{3}}\left(\frac{\varepsilon_{1}}{\varepsilon_{2}}\right)^{\frac{1}{3}}=\left(\frac{h_{2}}{h_{1}}\right)^{\frac{2}{3}} f^{\frac{4}{3}}\left(\frac{\varepsilon_{1}}{\varepsilon_{2}}\right)^{\frac{1}{3}}
$$

Eq. (29) may be solved for the combinations of $h_{2} / h_{1}$ and $f$ for which both $\varepsilon_{1}=\varepsilon_{2}$ and $T_{m 1}=T_{m 2}$, allowing scaling of both the large- and small-scale turbulence characteristics of the natural ecosystem. This yields

$$
f=\sqrt{\frac{h_{1}}{h_{2}}}
$$

In other words, the experimental mixing system must be designed to produce an integral length scale that compensates for the depth distortion between the experimental system and the natural system. The light extinction depth would have to be adjusted to maintain similarity as well; W. M. Kemp (Univ. of Maryland, unpubl. data) has shown that this is possible by adjusting the aspect ratio of the tank, while Peeters et al. (1993) report that diffusers and black tank walls accomplish much the same thing.

\section{Summary}

Designers of experimental ecosystem mixers must consider size, non-interference, cost, durability, benignity, wall shear, and scope, in addition to the turbulent mixing questions discussed previously. Chemical engineering studies offer several helpful guidelines. First, mixing parameters can be expressed in terms of mixer geometry and mixing rate through dimensional analysis, and quantified through experimentation. Second, scale models are a useful and inexpensive way to test different configurations. Third, mixing in enclosures can be separated conceptually into large-scale flow and small-scale shear. In general, experimental ecosystem enclosures should have enough flow to prevent localized stagnation and enough shear to mimic the range of natural turbulent energy dissipation rates.

Existing experimental ecosystem mixing designs vary widely. Rotating paddle mixers are the best characterized of the available schemes. They are capable of simulating large-scale mixing and water column turbulence reasonably, they benefit the most from chemical engineering mixing studies, and they are reasonably easy to maintain. However, they can be costly to implement and they do not balance boundary fluxes against interior mixing very well. Turbulence generated by oscillating grid mixers also is reasonably well characterized, although there appear to be few studies of largescale mixing in oscillating grid tanks. Short, rapid oscillations leave much of the water column undisturbed, but they result in very large gradients in turbulent energy near the grid. Passing the grid through the entire water column homogenizes the turbulence better, but interferes with organisms more. Oscillating grids also suffer from a mismatch between boundary fluxes and interior mixing. In situ flexible-wall enclosures offer a number of advantages related to initial conditions, volume, light, and temperature. However, 
unassisted mixing rates are very low in these enclosures and small-scale shear presumably is low as well. There are very few published studies of turbulence and mixing in flexible-wall enclosures, and there are very few descriptions of assisted mixing schemes. Other mixing schemes that have been used in experimental ecosystem enclosures include bubbling and pumping.

Benthic mesocosm designs vary even more than water column designs. The best benthic mesocosm designs reproduce both the general flow characteristics of the natural benthic environment and the details of the bottom boundary layer structure. However, these designs tend to be quite complex and expensive to implement. There have been limited attempts to reproduce both mixing of the water column and the flow environment of the benthos in a single, linked system; more work is needed.

There are a number of techniques available for measuring turbulent mixing in experimental ecosystcm enclosures. One of the simplest and most effective for determining large-scale mixing characteristics is dye dispersion, which can be used both for qualitative determination of mixing uniformity and for quantitative determination of a mixing time. Practitioners must be careful to use neutrally buoyant dye and to specify the injection location and degree of uniformity considered mixed, especially with regard to the definition of a mixing time. Gypsum dissolution techniques can be quite useful for measuring relative flow intensity, though some prior knowledge of the nature of the flow is necessary to interpret the results properly. If gypsum dissolution techniques are calibrated under similar conditions (i.e. similar ratios of fluctuating flow to steady flow, similar water chemistry, and similar gypsum block morphologyl, they can be a reasonable method for estimating absolute turbulence intensity and (potentially) dissipation rate. Direct flow measurements are the best method for quantifying turbulent velocity distributions in enclosures, with new, more user-friendly technologies easing the task. Estimates of boundary fluxes are possible through dissolution or hot-film measurements at the bottom and gas exchange measurements at the surface.

Dimensional analysis is a useful tool for both design. and analysis of ecosystem experiments. Dimensionally similar scale modeling may be possible under certain circumstances by taking advantage of some of the unavoidable artifacts of experimental ecosystem enclosures and mixing schemes.

\section{CONCLUSIONS}

The basic premise of this paper is that turbulence and turbulent mixing are integral aspects of aquatic ecosystems. If our experimental ecosystems are to mimic natural ecosystems, then we must be as concerned about turbulent mixing in our experiments as we are about light, temperature, salinity, nutrients, etc. Turbulent mixing in experimental ecosystem studies is not optional. It is necessary.

This paper has attempted to provide a framework for consideration of turbulent mixing in experimental ecosystem studies. It has described important characteristics of natural turbulence, identified important turbulence scales for experimental ecosystem studies, and discussed implementation and quantification of turbulent mixing in ecosystem enclosures. The reader is referred to section summaries for specific conclusions, which will not be repeated here.

A number of issues raised here require further investigation. We know little about relationships between turbulence variability and ecosystem variability. Interactions may occur at all scales, but what are the mechanisms and how important are they? We know little about microscale environments in turbulent aquatic ecosystems. Sharp gradients and patchy particle distributions have been predicted and in some cases observed at microscales, but many of these predictions have not been verified and their ecological effects have not been evaluated. In a practical sense, more work is needed on mixing schemes that adequately reproduce both mixing of the water column and the flow environment of the benthos. Flexible-wall in situ enclosures are an attractive option for many ecosystem experiments, but they are badly undermixed in their usual configuration; this problem can be and should be addressed. The possibility of scale model experimental ecosystem studies based on dimensional similarity should be investigated. More generally, standard protocols are needed for designing mixing systems and measuring turbulence in ecosystem studies.

It is unreasonable to expect that every mixing scheme in every experimental ecosystem will be completely general and optimal. Rather, ecosystem researchers should weigh the goals of their experiments against the costs of implementing a mixing scheme and the likely artifacts of design compromises. Turbulent mixing conditions in ecosystem enclosures should be characterized before experiments begin, and conditions should be monitored during experiments if necessary. When results are reported, the mixing configuration and turbulence characteristics should be reported as well.

Acknowledgements. I am grateful to many friends and colleagues for discussions leading to the writing of this paper, to the Applied Ocean Physics and Engineering Department at the Woods Hole Oceanographic Institution for their hospitality during its writing, and to V. Kennedy, E. Porter, C. Oviatt, 
A. Sanford, and several anonymous reviewers for their careful reviews and helpful suggestions. This research was supported by the Multiscale Environmental Ecosystem Research Center (MEERC) at the University of Maryland Center for Environmental Science (UMCES) through grant no. R 819640 from the U.S. Environmental Protection Agency. UMCES publication number 2796

\section{LITERATURE CITED}

Abraham G (1988) Turbulence and mixing in stratified tidal flows. In: Dronkers J, van Leussen W (eds) Physical processes in estuaries. Springer-Verlag, Berlin, p 149-180

Agrawal YC, Terray EA, Donelan MA, Hwang PA, Williams AJ III, Drennan WM, Kahma KK, Kitaigorodskii SA (1992) Enhanced dissipation of kinetic energy beneath surface waves. Nature 359:219-220

Alcaraz M, Saiz E, Calbet A (1994) Small-scale turbulence and zooplankton metabolism: effects of turbulence on heartbeat rates of planktonic crustaceans. Limnol Oceanogr 39:1465-1470

Alldredge AL, Cohen Y (1987) Can microscale chemical patches persist in the sea? Microelectrode study of marine snow, fecal pellets. Science 235:689-691

Asmus H, Asmus RM, Prins TC, Dankers N, Frances G, Maass B, Reise K (1992) Benthic-pelagic flux rates on mussel beds: tunnel and tidal flume methodology compared. Helgoländer Meeresunters 46:341-361

Baker MA, Gibson $\mathrm{CH}$ (1987) Sampling turbulence in the stratified ocean: statistical consequences of strong intermittency. J Phys Oceanogr 17:1817-1836

Bakke T (1990) Benthic mesocosms: II. Basic research in hardbottom benthic mesocosms. In: Lalli CM (ed) Enclosed experimental marine ecosystems: a review and recommendations, Vol 37. Springer-Verlag, New York, p $122-135$

Banse K (1982) Experimental marine ecosystem enclosures in a historical perspective. In: Grice GD, Reeve MR (eds) Marine mesocosms. Springer-Verlag, New York, p 11-24

Batchelor GK (1967) The theory of homogeneous turbulence, 5th edn. Cambridge University Press, Cambridge

Bennett AF, Denman. KL (1989) Large-scale patchiness due to an annual plankton cycle. J Geophys Res 94:823-829

Berge JA, Schaanning M, Bakke T, Sandoy KA, Skeie GM, Ambrose WG Jr (1986) A soft-bottom sublittoral mesocosm by the Oslofjord: description, performance and examples of application. Ophelia 26:37-54

Bonner JS. Hunt CD. Paul JF, Bierman VJ Jr (1992) Transport of low-level radioactive soil at deep-ocean disposal site. J Environ Eng 118:101-119

Bowen JD, Stolzenbach KD, Chisholm SW (1993) Simulating bacterial clustering around phytoplankton cells in a turbulent ocean. Limnol Oceanogr 38:36-51

Boyce FM (1974) Mixing within experimental enclosures: a cautionary note on the Limnocorral. J Fish Res Bd Can 31: 1400-1405

Browman HI (1996) Predator-prey interactions in the sea: commentaries on the role of turbulence. Mar Ecol Prog Ser 139:301-302

Brumley BH, Jirka GH (1987) Near-surface turbulence in a grid-stirred tank. J Fluid Mech 183:235-263

Brunk B, Weber-Shirk M, Jirka G, Lion LW (1996) Modeling natural hydrodynamic systems with a differential-turbulence column. J Hydra Eng 122:373-380

Buchholtz-ten Brink MR, Gust G, Chavis D (1989) Calibration and performance of a stured benthic chamber. Deep Sea
Res 36:1083-1101

Butman CA (1986) Larval settlement of soft-sediment invertebrates: some predictions based on analysis of near-bottom velocity profiles. In: Nihoul JCJ (ed) Marine interfaces ecohydrodynamics. Elsevier, Amsterdam, p 487-513

Butman CA (1987) Larval settlement of soft-sediment invertebrates: the spatial scales of pattern explained by active habitat selection and the emerging role of hydrodynamical processes. Oceanogr Mar Biol Annu Rev 25:113-165

Butman CA, Frechette M, Geyer WR (1994) Flume experiments on food supply to the blue mussel Mytilus edulis L. as a function of boundary-layer flow. Limnol Oceanogr 39: $1755-1768$

Cahoon LB (1988) Use of a whirling cup rotor to stir benthic chambers. Hydrobiologia 160:193-198

Cantwell BJ (1981) Organized motion in turbulent flow. Annu Rev Fluid Mech 13:457-515

Carey DA (1983) Particle resuspension in the benthic boundary layer induced by flow around polychaete tubes. Can $J$ Fish Aquat Sci 40:301-308

Carpenter SR (1996) Microcosm experiments have limited relevance for community and ecosystem ecology. Ecology 77 : $677-680$

Chao SY, Paluszkiewicz T (1991) The hydraulics of density currents over estuarine sills. J Geophys Res 96:7065-7076

Chapman AJ (1974) Heat transfer, 3rd edn. Macmillan Publishing, New York

Chrost RJ, Riemann B (1994) Storm-stimulated enzymatic decomposition of organic matter in benthic/pelagic coastal mesocosms. Mar Ecol Prog Ser 108:185-192

Conover RJ, Paranjape MA (1977) Comments on the use of a deep tank in planktological research. Helgol Wiss Meeresunters 30:105-117

Costello JH, Strickler JR, Marrase C, Trager G, Zeller R, Freise AJ (1990) Grazing in a turbulent environment: I. Behavioral response of a calanoid copepod, Centropages hamatus. Proc Natl Acad Sci USA 87:1648-1652

Crank J (1975) The mathematics of diffusion, 2nd edn. Clarendon Press, Oxford

Csanady GT (1973) Turbulent diffusion in the environment. D Reidel Publishing Company, Dordrecht

Dade BW (1993) Near-bed turbulence and hydrodynamic control of diffusional mass transfer at the sea floor. Limnol Oceanogr 38:52-69

Daehler CC, Strong DR (1996) Can you bottle nature? The roles of microcosms in ecological research. Ecology 77: 663-664

Davis RE (1985) Drifter observations of coastal surface currents during CODE: the statistical and dynamical views. J Geophys Res 90:4756-4772

Denman KL (1994) Scale-determining biological-physical interactions in oceanic food webs. In: Giller PS, Hildrew AG, Raffaelli DG (eds) Aquatic ecology: scale, pattern and process. Blackwell Scientific Publications, Oxford, p $377-399$

Denman KL, Gargett AE (1995) Biological-physical interactions in the upper ocean: the role of vertical and small scale transport processes. Annu Rev Fluid Mech 27: 225-255

Denny MW (1988) Biology and the mechanics of the waveswept environment. Princeton University Press, Princeton, $\mathrm{NJ}$

de Wilde PAWJ (1990) Benthic mesocosms: I. Basic research in soft-bottom benthic mesocosms. In: Lalli CM (ed) Enclosed experimental marine ecosystems: a review and recommendations, Vol 37 Springer-Verlag, New York, p $109-121$ 
Donaghay PL, Klos E (1985) Physical, chemical and biological responses to simulated wind and tidal mixing in experimental marine ecosystems. Mar Ecol Prog Ser 26:35-45

Dower JF, Miller TJ, Leggett WC (1997) The role of microscale turbulence in the feeding ecology of larval fish. Adv Mar Biol 31:169-220

Dyer KR, New AL (1986) Intermittency in estuarine mixing. In: Wolfe DA (ed) Estuarine variability. Harcourt Brace Jovanovich, Orlando, FL, p 321-339

Eckman JE, Werner FE, Gross TF (1994) Modelling some effects of behavior on larval settlement in a turbulent boundary layer. Deep Sea Res 41:185-208

Eppley RW, Loeller P, Wallace JGT (1978) Stirring influences the phytoplankton species composition within enclosed columns of coastal sea water. J Exp Mar Biol Ecol 32: $219-239$

Estrada M, Alcaraz M, Marrase C (1987) Effects of turbulence on the composition of phytoplankton assemblages in marine microcosms. Mar Ecol Prog Ser 38:267-281

Estrada M, Marrase C, Alcaraz M (1988) Phytoplankton response to intermittent stirring and nutrient addition in marine microcosms Mar Erol Prog Ser 48:225-234

Feijen J, Hoftmeester JJ (1992) Gradients in production scale bioreactors. In: King R (ed) Fluid mechanics and its applications. 10: Fluid mechanics of mixing: modelling, operations and experimental techniques. Kluwer Academic Publishers, Dordrecht, p 65-72

Fennessy MJ, Dyer KR, Huntley DA (1994) Size and settling velocity distributions of flocs in the Tamar Estuary during a tidal cycle. Neth J Aquat Ecol 28:275-282

Fernando HJS (1991) Turbulent mixing in stratified fluids. Annu Rev Fluid Mech 23:455-493

Findlay RH, Kim SL, Butman CA (1992) Colonization of freshly deposited barite and silica sediments by marine microorganisms in a laboratory flume flow. Mar Ecol Prog Ser 90:73-88

Fischer HB, List EJ, Koh RCY, Imberger J, Brooks NH (1979) Mixing in inland and coastal waters. Academic Press, Inc, New York

Galbraith PS, Kelley DE (1996) Identifying overturns in CTD profiles. J Atmos Oceanic Technol 13:688-702

Gargett AE (1989) Ocean turbulence. Annu Rev Fluid Mech 21:419-451

Garrett C (1989) A mixing length interpretation of fluctuations in passive scalar concentration in homogeneous turbulence. J Geophys Res 94:9710-9712

Geyer WR, Signell RP (1992) A reassessment of the role of tidal dispersion in estuaries and bays. Estuaries 15:97-108

Geyer WR, Smith JD (1987) Shear instability in a highly stratified estuary. J Phys Oceanogr 17:1668-1679

Gibson $\mathrm{CH}$ (1991) Turbulence, mixing, and heat flux in the ocean main thermocline. J Geophys Res 96:20403-20420

Gibson $\mathrm{CH}$, Thomas WH (1995) Effects of turbulence intermittency on growth inhibition of a red tide dinoflagellate, Gonyaulax. J Geophys Res 100:24841-24846

Glud RN, Gundersen JK, Revsbech NP, Jørgensen BB, Huettel $M$ (1995) Calibration and performance of the stirred flux chamber from the benthic lander Elinor. Deep Sea Res 42:1029-1042

Grant HL, Hughes BA, Vogel WM, Moillet A (1968) The spectrum of temperature fluctuation in turbulent flow. J Fluid Mech 34:423-442

Grant HL, Stewart RW, Moilliet A (1962) Turbulence spectra from a tidal channel. J Fluid Mech 12:241-263

Grant WD, Boyer LF, Sanford LP (1982) The effects of bioturbation on the initiation of motion of intertidal sands. J Mar Res 40:659-673
Grant WD, Madsen OS (1.986) The contmental-shelf bottom boundary layer. Annu Rev Fluid Mech 18:265-305

Grant WD, Williams AJ III, Glenn SM (1984) Bottom stress estimates and their prediction on the Northern California Continental Shelf during CODE-I: the importance of wave-current interaction. J Phys Oceanogr 14: $506-527$

Grassle JP, Butman CA, Mills SW (1992) Active habitat selection by Capitella sp. I. larvae. II. Multiple-choice experiments in still water and flume flows. J Mar Res 50:717-743

Gray C, Bruce T (1995) The application of particle image velocimetry (PIV) to offshore engineering. In: Proc 5th Int Offshore and Polar Engineering Conf, The Hague (The Netherlands), 11-16 June 1995, Vol 3. International Society of Offshore and Polar Engineers, Golden, CO, p $701-708$

Grice GD, Reeve MR (1982) Introduction and description of experimental ecosystems. In: Grice GD, Reeve MR (eds) Marine mesocosms. Springer-Verlag, New York, p 1-9

Grizzle RE, Langan R, Howell H (1992) Growth responses of suspension-feeding bivalve molluscs to changes in water flow: differences between siphonate and nonsiphonate taxa. J Exp Mar Biol Ecol 162:213-238

Grizzle RE, Langan R, Howell H (1994) Growth responses of Crassostrea virginica, Mercenaria mercenaria and Mytilus edulis to changes in water flow: a test of the inhalant pumping speed' hypothesis. J Shellfish Res 13:315

Gross TF, Nowell ARM (1983) Mean flow and turbulence scaling in a tidal boundary layer. Cont Shelf Res 2:109-126

Gross TF, Williams AJ, Terray EA (1994) Bottom boundary layer spectral dissipation estimates in the presence of wave motions. Cont Shelf Res 14:1239-1256

Guanguo L (1990) Different types of ecosystem experiments In: Lalli CM (ed) Enclosed experimental marine ecosystems: a review and recommendations, Vol 37 SpnngerVerlag, New York, p 7-19

Gust G (1977) Turbulence and waves inside flexible-wall systems designed for biological studies. Mar Biol 42:47-53

Gust G (1988) Skin friction probes for field applications. J Geophys Res 93:14121-14132

Haury LR, Yamazaki H, Itsweire EC (1990) Effects of turbulent shear flow on zooplankton distribution Deep Sea Res $37: 447-461$

Heathershaw AD (1976) Measurements of turbulence in the Irish Sea benthic boundary layer. In: McCave IN (ed) The benthic boundary layer. Plenum Press, New York, p 1 1-32

Hill PS, Nowell ARM, Jumars PA (1992) Encounter rate by turbulent shear of particles similar in diameter to the Kolmogorov scale. J Mar Res 50:643-668

Hopfinger EJ (1987) Turbulence in stratified fluids: a review. J Geophys Res 92:5287-5303

Horne JK, Schneider DC (1994) Analysis of scale-dependent processes with dimensionless ratios. Oikos 70:201-211

Howarth RW, Butler T, Lunde K, Swaney D, Chu CR (1993) Turbulence and planktonic nitrogen fixation: a mesocosm experiment. Limnol Oceanogr 38:1696-1711

Howerton RD, Boyd CE (1992) Measurement of water circulation in ponds with gypsum blocks. Aquacult Eng 11 $141-155$

Huettel M. Gust G (1992) Solute release mechanisms from confined sediment cores in stirred benthic chambers and flume flows. Mar Ecol Prog Ser 82:187-197

Hwang JS, Costello JH, Strickler JR (1994) Copepod grazing in turbulent flow: elevated foraging behavior and habituation of escape responses. J Plankton Res 16:421-431

Itsweire EC, Osborn TR (1988) Microstructure and vertical velocity shear distribution in Monterey Bay. In: Nihoul 
JCJ, Jamart BM (eds) Small-scale turbulence and mixing in the ocean. Elsevier, Amsterdam, p 213-228

Itsweire EC, Koseff JR, Briggs DA, Ferziger JH (1993) Turbulence in stratified shear flows: implications for interpreting shear-induced mixing in the ocean. J Phys Oceanogr 23: $1508-1522$

Jaehne B, Muennich KO, Boesinger R, Dutzi A, Huber W, Libner $P$ (1987) On the parameters influencing air-water gas exchange. J Geophys Res 92:1937-1949

Johnson AS, Sebens KP (1993) Consequences of a flattened morphology: effects of flow on feeding rates of the scleractinian coral Meandrina meandrites. Mar Ecol Prog Ser 99: $99-114$

Johnson GC, Lueck RG, Sanford TB (1994) Stress on the Mediterranean outflow plume: Part 2. Turbulent dissipation and shear measurements. J Phys Oceanogr 24: $2084-2092$

Jorgensen BB, Revsbech NP (1985) Diffusive boundary layers and the oxygen uptake of sediments and detritus. Limnol Oceanogr 30:111-122

Jumars PA (1993) Concepts in biological oceanography: an interdisciplinary primer. Oxford University Press, New York

Karp-Boss L, Boss E, Jumars PA (1996) Nutrient fluxes to planktonic osmotrophs in the presence of fluid motion. Oceanogr Mar Biol Annu Rev 34:71-107

Kent RE, Pritchard DW (1959) A test of mixing length theories in a coastal plain estuary. J Mar Res 18:62-72

Kiorboe T (1993) Turbulence, phytoplankton cell size, and the structure of pelagic food webs. Adv Mar Biol 29:1-72

Kiørboe T, Andersen KP, Dam HG (1990) Coagulation efficiency and aggregate formation in marine phytoplankton. Mar Biol 107:235-245

Klos E (1988) An experimental estuarine salunity gradient In: Proc Oceans 88 Conf. Institute of Electrical and Electronics Engineers, Piscataway, NJ, p 1529-1535

Koch EW (1994) Hydrodynamics, diffusion-boundary layers and photosynthesis of the seagrass Thalassia testudinum and Cymodocea nodosa. Mar Biol 118:767-776

Koself JR, Holen JK, Monismith SG, Cloern JE (1993) Coupled effects of vertical mixing and benthic grazing on phytoplankton populations in shallow, turbid estuaries. J Mar Res 51:843-868

Kotak BG, Robinson, GGC (1991) Artificially-induced water turbulence and the physical and biological features within small enclosures. Arch Hydrobiol 122:335-349

Kraus NC, Lohrmann A, Cabrera R (1994) New acoustic meter for measuring 3-d laboratory flows. J Hydra Eng 120 $406-412$

Kuiper J, Brockmann UH, van het Groenewoud H, Hoornsman G, Hammer KD (1983) Influences of bag dimensions on the development of enclosed plankton communities during POSER. Mar Ecol Prog Ser 14:9-17

Kundu PK (1990) Fluid mechanics. Academic Press, Inc, San Diego

Landahl MT, Mollo-Christensen E (1986) Turbulence and random processes in fluid mechanics. Cambridge University Press, Cambridge

Landry F, Miller TJ, Leggett WC (1995) The effects of smallscale turbulence on the ingestion rate of fathead minnow (Pimephales promelas) larvae. Can J Fish Aquat Sci 52: $1714-1719$

Lasker JK (1981) Factors contributing to variable recruitment of the northern anchovy (Engraulis mordax) in the California Current: contrasting years, 1975 through 1978. Rapp PV Réun Comm Int Explor Mer 178:375-388

Lasserre P (1990) Marine microcosms: small-scale controlled ecosystems. In: Lalli CM (ed) Enclosed experimental marine ecosystems: a review and recommendations, Vol 37. Springer-Verlag, New York, p 20-60

Lazier JRN. Mann KH (1989) Turbulence and the diffusive layers around small organisms. Deep Sea Res 36:1721-1733

Ledwell JR, Watson AJ, Law CS (1993) Evidence for slow mixing across the pycnocline from an open-ocean tracerrelease experiment. Nature 364:701-703

Legendre L (1981) Hydrodynamic control of marine phytoplankton production: the paradox of stability. In: Nihoul JCJ (ed) Ecohydrodynamics. Elsevier Scientific, Amsterdam, p 191-208

Legendre L, Legendre P (1983) Numerical ecology. Elsevier Scientific, Amsterdam

Lehfeldt R, Bloss S (1988) Algebraic turbulence model for stratified tidal flows. In: Dronkers J, van Leussen W (eds) Physical processes in estuaries. Springer-Verlag, Berlin, p 278-294

Lewis MR, Cullen JJ, Platt T (1984a) Relationships between vertical mixing and photoadaptataion of phytoplankton: similarity criteria. Mar Ecol Prog Ser 15:141-149

Lewis MR, Horne EPW, Cullen JJ, Oakey NS, Platt T (1984b) turbulent motions may control phytoplankton photosynthesis in the upper ocean. Nature 311:49-50

Lewis MR, Platt T (1982) Scales of variability in estuarine ecosystems. In: Kennedy VS (ed) Estuarine comparisons. Academic Press, New York, p 3-20

List EJ, Gartrell G, Winant CD (1990) Diffusion and dispersion in coastal waters. J Hydra Eng 116:1158-1179

Macintyre S (1993) Vertical mixing in a shallow, eutrophic lake: possible consequences for the light climate of phytoplankton. Limnol Oceanogr 38:798-817

MacIntyre S, Alldredge AL, Gotshalk CC (1995) Accumulation of marine snow at density discontinuities in the water column. Limnol Oceanogr 40:449-468

MacKenzie BR, Leggett WC (1993) Wind-based models for estimating the dissipation rates of turbulent energy in aquatic environments: empirical comparisons. Mar Ecol Prog Ser 94:207-216

Mann KH, Lazier JRN (1991) Dynamics of marine ecosystems: biological-physical interactions in the oceans. Blackwell Scientific Publications, Cambridge, MA

Marrase C, Costello JH, Granata T, Strickler JR (1990) Grazing in a turbulent environment: energy dissipation, encounter rates, and efficacy of feeding currents in Centropages hamatus. Proc Natl Acad Sci USA 87:1653-1657

Mehta AJ (1988) Laboratory studies on cohesive sediment deposition and erosion. In: Dronker J, van Leussen W (eds) Physical processes in estuaries. Springer-Verlag, Berlin. p $427-445$

Menzel DW, Case J (1977) Concept and design: controlled ecosystem pollution experiment. Bull Mar Sci 27:1-7

Middleton JH, Griffin DA, Moore AM (1993) Oceanic circulation and turbulence in the coastal zone. Cont Shelf Res 13: $143-168$

Miller DC, Jumars PA, Nowell ARM (1984) Effects of sediment transport on deposit feeding: scaling arguments. Limnol Oceanogr 29:1202-1217

Moeseneder MM, Herndl GJ (1995) Influence of turbulence on bacterial production in the sea. Limnol Oceanogr 40 : $1466-1473$

Monismith SG, Koseff JR, Thompson JK, O'Riordan CA, Nepf HM (1990) A study of model bivalve siphonal currents. Limnol Oceanogr 35:680-696

Moore PA, Zimmer-Faust RK, Bement SL, Weissburg MJ, Parrish JM, Gerhardt GA (1992) Measurement of microscale patchiness in a turbulent aquatic odor plume using a semi- 
conductor-based microprobe. Biol Bull (Woods Hole) 183: $138 \quad 142$

Moum JN (1996) Energy-containing scales of turbulence in the ocean. J Geophys Res 101:14095-14109

Muelbert JH, Lewis MR, Kelley DE (1994) The importance of small-scale turbulence in the feeding of herring larvae. J Plankton Res 16:927-944

Muschenheim DK (1987) The dynamics of near-bed seston flux and suspension-feeding benthos. J Mar Res 45: 473-496

Muschenheim DK, Grant J, Mills EL (1986) Flumes for benthic ecologists: theory, construction and practice. Mar Ecol Prog Ser 28:185-196

Nixon SW, Oviatt CA, Buckley BA (1979) Turbulent mixing in marine microcosms - some relative measures and ecological consequences. In: Jacoff FS (ed) Advances in marine environmental research-proceedings of a symposium. US EPA, Environmental Research Lab, Narragansett, RI, p 382-409

Nixon SW, Alonso D, Pilson MEQ, Buckley BA (1980) Turbulent mixing in aquatic microcosms. In: Giesy JP (ed) Microcosms in ecological research. DOE Symposium Series, Augusta, GA, p 818-849

Nowell ARM, Jumars PA (1984) Flow environments of aquatic benthos. Annu Rev Ecol Syst 15:303-328

Nowell ARM, Jumars PA (1987) Flumes: theoretical and experimental considerations for simulation of benthic environments. Oceanogr Mar Biol Annu Rev 25:91-112

Øiestad V (1990) Specific application of meso- and macrocosms for solving problems in fisheries research. In: Lalli CM (ed) Enclosed experimental marine ecosystems: a review and recommendations, Vol 37 Springer-Verlag, New York, p 136-154

Okubo A (1971) Oceanic diffusion diagrams. Deep Sea Res 18:789-802

Okubo A (1980) Diffusion and ecological problems: mathematical models. Springer-Verlag, New York

Oldshue JY, Herbst NR (1990) A guide to fluid mixing. Mixing Equipment Company, Rochester, NY

Opdyke BN, Gust G, Ledwell JR (1987) Mass transfer from smooth alabaster surfaces in turbulent flows. Geophys Res Lett 14:1131-1134

O'Riordan CA, Monismith SG, Koseff JR (1993) A study of concentration boundary layer formation of a bed of model bivalves. Limnol Oceanogr 38:1712-1729

Osborn TR (1980) Estimates of the local rate of vertical diffusion from dissipation measurements. J Phys Oceanogr 10 : $83-89$

Osborn T, Scotti A (1996) Effect of turbulence on predatorprey contact rates: where do we go from here? Mar Ecol Prog Ser 139:302-304

Oviatt C (1994) Biological considerations in marine enclosure experiments: challenges and revelations. Oceanography $7: 45-51$

Oviatt CA, Perez KT, Nixon SW (1977) Multivariate analysis of experimental marine ecosystems. Helgol Wiss Meeresunters 30:30-46

Patel VC, Rodi W, Scheuerer G (1985) Turbulence models for near-wall and low Reynolds number flows: a review. Am Inst Aeronaut Astronaut J 23:1308-1319

Patterson MR (1992) A mass transfer explanation of metabolic scaling relations in some aquatic invertebrates and algae. Science 255:1421-1423

Pawlik JR, Butman CA (1993) Settlement of a marine tube worm as a function of current velocity: interacting effects of hydrodynamics and behavior. Limnol Oceanogr 38 $1730-1739$
Peeters JCH, Arts F, Escaravage V, Haas HA, de Jong JEA, van Loon R, Moest B, van der Put A (1993) Studies on light climate, mixing and reproducibility of ecosystem variables in mesocosm: consequences for the design. In: Peeters $\mathrm{JCH}$, Joordens JCA, Smaal AC, Nienhuis PH (eds) The impact of marine eutrophication on phytoplankton and benthic suspension feeders: results of a mesocosm pilot study. Dienst Getijde wateren, Middelburg, Netherlands. Report DGW-93039 / NIOO/CEMO-654, p 7-23

Penry D (1989) Tests of kinematic models for deposit-feeders' guts: patterns of sediment processing by Parastichopus californicus (Stimpson) (Holothuroidea) and Amphicteis scaphobranchiata Moore (Polychaeta). J Exp Mar Biol Ecol 128:127-146

Peters F, Gross $T$ (1994) Increased grazing rates of microplankton in response to small-scale turbulence. Mar Ecol Prog Ser 115:299-307

Peters H, Gregg MC, Sanford TB (1994) The diurnal cycle of the upper equatorial ocean: turbulence, fine-scale shear, and mean shear. J Geophys Res 99:7707-7723

Petticrew EL, Kalff J (1991) Calibration of a gypsum source for freshwater flow measurements. Can J Fish Aquat Sci 48 : $1244-1249$

Platt $\Upsilon$ (1981) Thinking in terms of scale: introduction to dimensional analysis. In: Platt $\mathrm{T}$, Mann $\mathrm{KH}$, Ulanowicz RE (eds) Mathematical models in biological oceanography. UNESCO Press, Paris, p 112-121

Porter ET, Newell RIE, Sanford LP (1997) The effect of bivalves and water flow on benthic-pelagic coupling in shallow coastal ecosystems. In: Abstracts of the ASLO Aquatic Sciences Meeting, Santa Fe, NM, February, 1997. Lewis International, Inc, Halifax, NS, p 271-272

Prins TC, Escaravage V, Pouwer AJ, Haas HA (1994) Description of mesocosms, methods and comparison with North Sea conditions. In: Smaal AC, Peeters JCH, Haas HA, Heip CHR (eds) The impact of marine eutrophication on phytoplankton and benthic suspension feeders. Progress report I: results of mesocosm experiments with reduced P-load and increased grazing pressure. Ministry of Transport, Public Works and Water Management, DirectorateGeneral of Public Works and Water Management, National Institute for Coastal and Marine Management/RIKZ, Middelburg, Netherlands, Report RIKZ 94.035 / NIOO/CEMO - 1994.2, p 10-40

Richardson LF (1922) Weather prediction by numerical process. Cambridge University Press, Cambridge

Richardson PL (1993) Tracking ocean eddies. Am Sci 81 261-271

Riemann B, Nielsen TG, Horsted SJ, Koefoed Bjornsen P. Pock-Steen J (1988) Regulation of phytoplankton biomass in estuarine enclosures. Mar Ecol Prog Ser 48:205-215

Rothschild BJ, Osborn TR (1988) Small-scale turbulence and plankton contact rates. J Plankton Res 10:465-474

Saiz E, Alcaraz M, Paffenhofer GA (1992) Effects of smallscale turbulence on feeding rate and gross-growth efficiency of three Acartia species (Copepoda: Calanoida). J Plankton Res 14:1085-1097

Sanford LP, Chang ML (1997) The bottom boundary condition for sediment deposition. J Coast Res SI 25:3-17

Sanford LP, Halka JP (1993) Assessing the paradigm of mutually exclusive erosion and deposition of mud, with examples from upper Chesapeake Bay. Mar Geol 114:37-57

Santschi PH, Anderson RF, Fleisher MQ, Bowles W (1991) Measurements of diffusive sublayer thicknesses in the ocean by alabaster dissolution, and their implications for the measurements of benthic fluxes. J Geophys Res 96 : 10641-10657 
Schubert H, Matthijs HCP, Mur LR, Schiewer U (1995) Blooming of cyanobacteria in turbulent water with steep light gradients: the effect of intermittent light and dark periods on the oxygen evolution capacity of Synechocystis sp. PCC 6803. FEMS Microbiol Ecol 18:237-245

SCOR Working Group 69 (1988) Small-scale turbulence and mixing in the ocean: a glossary. In: Nihoul JCJ, Jamart BM (eds) Small-scale turbulence and mixing in the ocean. Elsevier, Amsterdam, p 3-10

SCOR Working Group 85 (1990) Introduction. In: Lalli CM (ed) Enclosed experimental marine ecosystems: a review and recommendations. Sprunger-Verlag, New York, p 1-6

Shapiro AH (1961) Shape and flow. Doubleday and Company, lnc, Garden City, NY

Shimeta J, Jumars PA (1991) Physical mechanisms and rates of particle capture by suspension-feeders. Oceanogr Mar Biol Annu Rev 29:191-257

Silverberg N, Gagnon JM, Lee K (1995) A benthic mesocosm facility for maintaining soft-bottom sediments. Neth $J$ Sea Res 34:289-302

Smith IR (1975) Turbulence in lakes and rivers. Freshwater Biological Association, Ambleside, Cumbria, Sci Publ no. 29

Snelgrove PVR, Butman CA (1994) Animal-sediment relationships revisited: cause versus effect. Oceanogr Mar Biol Annu Rev 32:111-117

Snelgrove PVR, Butman CA, Grassle JF (1995) Potential flow artifacts associated with benthic experimental gear: deepsea mudbox examples. J Mar Res 53:821-845

Sonntag NC, Parsons TR (1979) Mixing an enclosed, 1300 cubic meter water column: effects on the planktonic food web. J Plankton Res 1:85-102

Squires KD, Yamazaki H (1995) Preferential concentration of marine particles in isotropic turbulence. Deep Sea Res I 42:1989-2004

Steele JH, Farmer DM, Henderson EW (1977) Circulation and temperature structure in large marine enclosures. J Fish Res Bd Can 34:1095-1104

Sundby S, Fossum P (1990) Feeding conditions of Arcto-Norwegian cod larvae compared with the Rothschild-Osborn theory on small-scale turbulence and plankton contact rates. J Plankton Res 12:1153-1162

Taghon GL, Greene RR (1992) Utilization of deposited and suspended particulate matter by benthic 'interface' feeders. Limnol Oceanogr 37:1370-1391

Takahashi M, Whitney FA (1977) Temperature, salinity and light penetration structures: controlled ecosystem pollution experiment. Bull Mar Sci 27:8-16

Tatterson GB (1991) Fluid mixing and gas dispersion in ag1tated tanks. McGraw-Hill, Inc, New York

Taylor AH, Stephens JA (1993) Diurnal variations of convective mixing and the spring bloom of phytoplankton. Deep Sea Res 40:389-408

Tennekes H, Lumley $J L$ (1972) A first course in turbulence. MIT Press, Cambridge, MA

Tenore KR (1987) Nitrogen in benthuc food chains. In: Blackburn TH. Sorensen J (eds) Nitrogen cycling in coastal marine environments. Wiley, New York, p 191-206

Terray EA, Donelan MA, Agrawal YC, Drennan WM, Kahma KK, Williams AJ III, Hwang PA, Kitaigorodskii SA (1996)

Editorial responsibility: Otto Kinne (Editor),

Oldendorf/Luhe, Germany
Estimates of kinetic energy dissipation under breaking waves. J Phys Oceanogr 26:792-807

Thomas WH, Gibson CH (1992) Effects of quantified smallscale turbulence on the dinoflagellate, Gymnodinium sanguineum (splendens): contrasts with Gonyaulax (Lingulodinium) polyedra, and the fishery implication. Deep Sea Res 39:1429-1437

Thompson TL, Glenn EP (1994) Plaster standards to measure water motıon. Limnol Oceanogr 39:1768-1779

Threlkeld ST (1994) Benthic-pelagic interactions in shallow water columns: an experimentalist's perspective. Hydrobiologia 275/276:293-300

Townsend AA (1976) The structure of turbulent shear flow, 2nd edn. Cambridge University Press, Cambridge

Trivett DA, Snow JW (1995) Combined velocity-density-vortucity sensor: fully three-dimensional acoustic flow sensor measures small-scale velocities, physical measurements simultaneously. Sea Technol 36:27-32

Turner JS (1973) Buoyancy effects in fluids. Cambridge University Press, Cambridge

van Leussen W (1988) Aggregation of particles, settling velocity of mud flocs: a review. In: Dronkers J, van Leussen W (eds) Physical process in estuaries. Springer-Verlag, Berlin, p 347-403

van Leussen $W$ (1997) The Kolmogorov microscale as a limiting value for the floc sizes of suspended fine-grained sediments in estuaries. In: Burt $N$, Parker R, Watts $J$ (eds) Cohesive sediments. John Wiley and Sons, New York, p 45-62

Watanabe M. Kohata K, Kimura T, Takamatsu T, Yamaguchi $S$, loriya $I$ (1995) Generation of a Chattonella antiqua bloom by imposing a shallow nutricline in a mesocosm. Limnol Oceanogr 40:1447-1460

Weetman RJ (1992) Development of transitional flow impeller. In: King R (ed) Fluid mechanics and its applications, 10: Fluid mechanics of mixing: modelling, operations and experimental techniques. Kluwer Academic Publishers, Dordrecht, p 19-26

Weinstock J (1992) Vertical diffusivity and overturning length in stably stratified turbulence. J Geophys Res 97: $12653-12658$

Williams AJ III, Tochko JS, Koehler RL, Grant WD, Gross TF, Dunn CVR (1987) Measurement of turbulence in the oceanic bottom boundary layer with an acoustic current meter array. J Atmos Oceanic Technol 4:312-327

Wolanski E, Gibbs RJ, Mazda Y, Mehta A, King B (1992) The role of turbulence in the settling of mud flocs. J Coast Res 8:35-46

Wright LD, Boon JD, Xu JP, Kim SC (1992) The bottom boundary layer of the Bay Stem Plains environment of lower Chesapeake Bay Estuarine. Coast Shelf Sci 35:17-36

Yamazaki H, Lueck R (1990) Why oceanic dissipation rates are not lognormal. J Phys Oceanogr 20:1907-1918

Yamazaki H, Osborn TR (1988) Review of oceanic turbulence: implications for biodynamics. In: Rothschild BJ (ed) Toward a theory on biological-physical interactions in the world ocean. Kluwer Academic Publishers, Dordrecht, p 215-234

Yamazaki H, Osborn T (1990) Dissipation estimates for stratified turbulence. J Geophys Res 95:9739-9744

Submitted: January 6, 1997; Accepted: September 23, 1997

Proofs received from author(s): December 22, 1997 